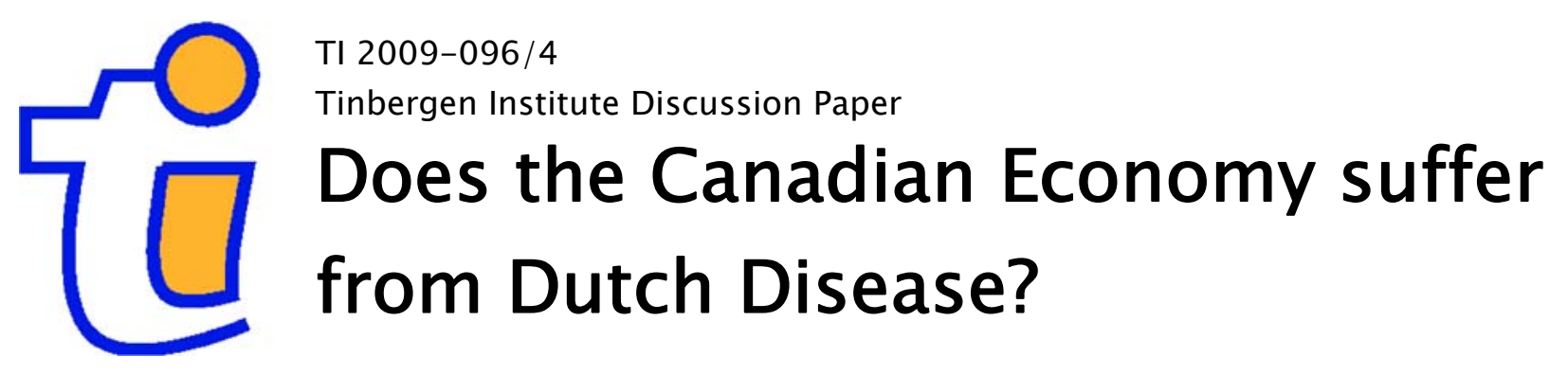

Michel Beinel

Charles S. Bos²

Serge Coulombe 3

' University of Luxembourg, Luxembourg, CESifo;;

2 VU University of Amsterdam, The Netherlands, and Tinbergen Institute;

3 University of Ottawa, Canada. 


\section{Tinbergen Institute}

The Tinbergen Institute is the institute for economic research of the Erasmus Universiteit Rotterdam, Universiteit van Amsterdam, and Vrije Universiteit Amsterdam.

Tinbergen Institute Amsterdam

Roetersstraat 31

1018 WB Amsterdam

The Netherlands

Tel.: +31(0)205513500

Fax: $+31(0) 205513555$

Tinbergen Institute Rotterdam

Burg. Oudlaan 50

3062 PA Rotterdam

The Netherlands

Tel.: + $31(0) 104088900$

Fax: $+31(0) 104089031$

Most TI discussion papers can be downloaded at http://www.tinbergen.nl. 


\title{
Does the Canadian Economy Suffer from Dutch Disease?
}

\author{
Michel Beine,${ }^{*}$ Charles S. Bos ${ }^{\dagger}$ and Serge Coulombe ${ }^{\mathbb{*}}$
}

November 2009

\begin{abstract}
We argue that the failure to disentangle the evolution of the Canadian currency from the U.S. currency leads to potentially incorrect conclusions regarding the case of Dutch disease in Canada. We propose a new approach that is aimed at extracting both currency components and energy- and commodity-price components from observed exchange rates and prices. We first analyze the separate influence of commodity prices on the Canadian and the U.S. currency components. We then estimate the separate impact of the two currency components on the shares of manufacturing employment in Canada. We show that 42 per cent of the manufacturing employment loss that was due to exchange rate developments between 2002 and 2007 is related to the Dutch disease phenomenon. The remaining 58 per cent of the employment loss can be ascribed to the weakness of the U.S. currency.
\end{abstract}

Keywords: Dutch disease; Natural resources; Exchange rates; Currency components; Bayesian econometrics.

JEL classification: C11; F31; O13; O51

\section{Introduction}

Dutch disease refers to the case where a resource boom in an economy leads to a real exchange appreciation and to the crowding out of the tradable manufacturing sector. As phrased by Krugman (1987), the interesting question is why this phenomenon should be

\footnotetext{
${ }^{*}$ University of Luxembourg, Luxembourg, and CES-IFO

${ }^{\dagger}$ Tinbergen Institute and VU University Amsterdam, Amsterdam, The Netherlands

${ }^{\ddagger}$ University of Ottawa, Ottawa, Canada

${ }^{\S}$ The research in this paper has been supported by Industry Canada. The views expressed in this paper are those of the authors and do not necessarily reflect those of Industry Canada. E-mail addresses are michel.beine@uni.lu; cbos@feweb.vu.nl; scoulomb@uottawa.ca. The authors thank Robert Vermeulen for assistance and Ram Acharya for providing us with data. The paper benefited from useful comments and suggestions by participants of the ERAC seminar of Industry Canada, Ottawa, of the CES-IFO annual workshop in Munich, at GREQAM seminar in Marseille and at the 3rd workshop of the MIFN network in Luxembourg. We thank in particular Ram Acharya, Guglielmo Caporale, Yin-Wang Cheung, Paul De Grauwe, Gernot Doppelhoffer, Robert Lafrance, Richard Roy, and Simon van Norden.
} 
regarded as a disease. According to Krugman, it becomes a disease when the manufacturing sector does not rebound after the resource boom. Various forms of non-convexities are all good reasons why this might be the case. For instance, Krugman (1991) and Venables (1996) emphasize the idea of critical mass and suggest there are levels below which further contraction of an industry is difficult to reverse. Furthermore, Krugman (1987) suggests that de-industrialization might be detrimental for the whole economy in the long run since the manufacturing sector is characterized by learning-by-doing effects.

The underlying mechanism of the Dutch disease is that the real exchange rate of the resource-rich economy tends to appreciate strongly with the rise of the export revenues from the resource sector. In turn, the appreciation harms the economy's exports from the manufacturing sector, leading over time to de-industrialization. ${ }^{1}$ The name of the phenomenon comes from a 1977 article in The Economist (1977 Nov 26: 82-83) that described the shrinking of The Netherlands' manufacturing sector following the discovery of important reserves in natural gas. ${ }^{2}$

Between 2002 and 2008, the spectacular rise in commodity and oil prices has led to significant growth of the Canadian energy and commodity sectors. This is illustrated by the remarkable development of the Athabasca oil sands in the northern part of the province of Alberta. While the extraction of oil from tar sands is difficult and costly, the rise in oil prices to new highs has triggered a significant expansion of the extraction and export of the oil. This in turn has led to a big increase in Alberta's nominal GDP per capita, an impressive improvement in the provincial public finances, and important spillovers for other provinces. ${ }^{3}$ During the same period, the Canadian exchange rate appreciated and the manufacturing sector contracted.

While the rise in energy and commodity prices brings obvious benefits for Canada as a whole, it has also raised many concerns for policy-makers and economists. Most of the concerns relate to the possibility that the Canadian economy could be subject to the Dutch disease phenomenon. From the recently observed decrease in manufacturing employment, most analysts currently take it for granted that the Canadian economy is negatively affected by the appreciation of the Canadian dollar (CAD) against the U.S. dollar (USD). They also strongly believe that the Canadian dollar is driven mostly by oil and commodity prices. ${ }^{4}$ In the meantime, the brutal fall in prices for oil and other commodities following the worsening of the financial crisis in fall 2008 has put a sudden end to the Canadian resource boom. Despite a slight depreciation of the Canadian

\footnotetext{
${ }^{1}$ Classical references on the Dutch diseases also include Corden and Neary (1982) and Corden (1984).

${ }^{2}$ The Dutch disease might be seen as one particular mechanism explaining the so-called natural resource curse, i.e., the observation that countries rich in natural resources tend to exhibit poor performances in terms of economic development. On this topic, see, among many others, Sachs and Warner (1995, 1999), Gylfason et al. (1999); Gylfason (2001), and Stijns (2005).

${ }^{3}$ Between 2004 and 2006, net interprovincial migration to Alberta accounted for an increase of 114,000, or 3.3 per cent, in Alberta's population. At the peak of the oil boom in 2006, weekly flights were established between Fort McMurray in northern Alberta at the heart of the Athabasca region and St. John's, Newfoundland.

${ }^{4}$ See, for instance, the papers and transcripts of oral interventions of a conference entitled "Implications for Canada of a High-Valued Canadian Dollar. Has the Canadian Economy Caught Dutch Disease?", Toronto, January 2008. The transcripts are available at http://www.ppforum.ca.
} 
dollar starting in fall 2008 that could have helped manufacturing exports, the Canadian manufacturing sector was further shaken by the worsening of the U.S. economy. In its February 2009 budget, the Canadian federal government announced the creation of the Southern Ontario Development Agency to promote economic diversification and restructuring in Canada's industrial core. Before this announcement, southern Ontario was the only Canadian region without a regional development agency.

A growing academic literature also addresses questions related to the Dutch disease hypothesis. For the issue at stake here, there are two interesting and complementary threads in the literature. The first tests whether the CAD/USD exchange rate is driven in the long run by oil and commodity prices. ${ }^{5}$ These analyses basically revisit the exchange rate equation of Amano and van Norden (1995) and conclude, with some nuances, that over the recent period, the CAD and USD have become currencies driven both up and down by the evolution of commodity and oil prices. A second thread Coulombe et al. (2007); Acharya and Coulombe (2008) aims at capturing the impact of fluctuations of the CAD and USD on the evolution of Canadian manufacturing output and employment. It provides strong evidence for attributing the substantial adjustment in employment to the strong appreciation of the Canadian dollar over the 2002-2007 period.

In this paper, we revisit the issue of the Dutch disease affecting the Canadian economy. We first argue that the evidence provided by the existing literature is insufficient to assess the importance of such a phenomenon in Canada. The main reason is that, basically, two conditions need to be fulfilled before ascribing the recent evolution of the Canadian manufacturing sector to the Dutch disease. First, the evolution of the Canadian currency should clearly be driven by the evolution of energy and/or commodity prices. Second, the part of the appreciation that is associated with commodity and/or energy prices should negatively affect Canadian employment in the manufacturing sector. By looking just at the bilateral CAD/USD exchange rate, the existing literature is unable to extract that part of the evolution affected by commodity and oil prices. By definition, an appreciation of the bilateral CAD/USD is driven by the strength of the CAD. However, it is also driven by the weakness of the USD whose evolution might be independent of those commodity prices. Our results support this conjecture. Therefore, from the observed evolution of the CAD and USD, one needs to disentangle the movement of the CAD that might be related to the variation in commodity prices from the movement of the Canadian dollar associated with the evolution of the USD. Even in the presence of the Dutch disease effect, a failure to disentangle both currency components will lead to a possible bias in estimating the magnitude of the effect. The drawback of using the traditional approach, based on the use of the bilateral exchange rate, is particularly serious since the recent period (2002-2008Q3) exhibits three concurrent evolutions: (1) an appreciation of the CAD in effective terms, (2) a sharp depreciation of the USD in effective terms, and finally (3) a strong increase in commodity and oil prices. By looking at the relationship between the CAD/USD and the commodity prices, the analysis implicitly assumes that those prices will affect the two currencies symmetrically. We show

\footnotetext{
${ }^{5}$ See, among others, Maier and DePratto (2008); Issa et al. (2006); Bayoumi and Mühleisen (2006) and Helliwell et al. (2004).
} 
that this assumption is strongly rejected by the data and, as a result, tackling this issue requires another approach.

Will the use of effective exchange rates do the job? Effective exchange rates are very often used as indexes of the strength of a particular currency. Unfortunately, in the case of the Canadian dollar, the effective exchange rate will be similar to the bilateral CAD/USD exchange rate as a very large part of the Canadian trade is with the United States (In 2006, the United States supplied 65 per cent of the Canadian imports and purchased 79 per cent of Canada's merchandise exports). ${ }^{6}$ As a result, the use of the Canadian effective exchange rate would be subject to the same previously mentioned problem. In the current paper, we provide another approach that aims at solving this issue.

Using the original Bayesian approach of Bos and Shephard (2006), we extract from a set of bilateral exchange rates the currency components that capture the strength of currencies such as the CAD and USD. Significantly, our method is fully independent of the trade weights that are usually used to define effective exchange rates. It is then possible to assess whether and how much each currency component is associated with the evolution of the commodity prices. This approach in turn allows us to quantify the part of the recent loss of the Canadian manufacturing employment that is associated with the recent increase of the commodity prices, accounting for the movements of the $\mathrm{CAD}$ and the USD that are unrelated to the evolution of those prices.

Our analysis provides simple but significant figures and conclusions concerning the case for the Dutch disease in Canada. First, we show that the recent dramatic appreciation of the CAD/USD exchange rate (around 48 per cent) might be decomposed into a 42 per cent appreciation of the Canadian currency and a 58 per cent depreciation of the U.S. currency. Second, the decomposition of the Canada-U.S. bilateral exchange rate into a USD component and a CAD component sheds new light on the relationship between the Canadian exchange rate and energy and commodity prices. Third, and more importantly, given the estimated respective responses of the Canadian employment to the evolution of each currency component, we find in the end that only 42 per cent of the CAD/USD appreciation affecting Canadian employment might be ascribed to the rise in commodity prices. Finally, our approach allows the identification of manufacturing sectors that have been subject to the Dutch disease, i.e., those in which the decrease in activity might be directly related to the rise in oil and commodity prices.

This paper is organized as follows. The second section reports some stylized facts, emphasizing the need for a new approach. Section three presents the econometric approach and reports the extracted currency components. Section four revisits the Amano-van Norden equation, using our new approach. Section five analyzes the impact of the evolution of the currency components on the Canadian manufacturing employment. Section 6 contains our conclusions.

\footnotetext{
${ }^{6}$ The empirical analysis of Coulombe et al. (2007) illustrates well how the 1989 Canada-United States Free Trade Agreement has exerted a significant positive long-run effect on GDP per capita.
} 


\section{Dutch disease and Canadian stylized facts}

\subsection{The economics of Dutch disease}

The original term Dutch disease refers to the adverse effects on the trade exposed manufacturing sector of the booming tradable sector in the economy. In the case of the Dutch economy, the booming tradable sector was the natural gaz sector. After the discovery of the gaz in the late 60 's, one observed an appreciation of the Dutch real exchange rate and a crowding out effect of the Dutch manufacturing industry. The subsequent literature analyzing this phenomenon has extended the scope of the Dutch disease analysis to other situations. It has also clarified the mechanisms at stake leading to the observed appreciation and the crowding out effect of the trade exposed manufacturing sector. In order to understand whether our analysis of the Canadian economy is associated to the Dutch disease phenomenon, it is first important to review the key elements of the Dutch disease literature.

As explained by Corden and Neary (1982) and Corden (1984), the Core model used to analyse the Dutch disease phenomenon makes a distinction between three sectors: a booming tradable sector $(\mathrm{B})$, a non tradable sector $(\mathrm{N})$ and a lagging tradable sector (L). In our case, the booming sector (B) comprises the commodity sector and the oil industry while the L sector includes the Canadian trade exposed sector. Given the openness degree of the Canadian economy, a major part of the manufacturing sector might be considered trade exposed. As explained by Corden (1984), the initial shock to the economy associated to the Dutch disease might be threefold: (i) an exogenous rise in the world price of the product of sector B, (ii) an exogenous positive productivity shock affecting sector B and (iii) a windfall discovery of the resources produced by sector B. For the Canadian economy, the initial shock might be seen as a mix of type (i) and (ii). The spectacular rise in the price of non energy commodities and oil around 2000 is obviously an important shock that might create a Dutch disease phenomenon in Canada. Furthermore, sustained technological progress in the oil industry over the last 30 years has continuously contributed at decreasing the cost of the extracting process.

In the Core model, the real appreciation of the exchange rate is due to two main effects, namely a spending effect and a resource reallocation effect. On one hand, the additional income generated by sector $\mathrm{B}$ leads to an increase of the price in the non tradable sector $(\mathrm{N})$, leading to a real appreciation of the currency. On the other hand, the higher profitability in $\mathrm{B}$ leads to an excess demand for labour in $\mathrm{B}$, which in turn induces a movement of labour out of $\mathrm{N}$ and out of $\mathrm{L}$ into B. Furthermore, the rise in the price in non tradables creates excess demand for $\mathrm{N}$ at the expense of $\mathrm{L}$. These two labour movement leads to a decrease in the activity of $\mathrm{L}$. If $\mathrm{L}$ is the (trade exposed) manufacturing sector and B the commodity and oil sectors, this leads to de-industrialisation. This analysis implicitly rests on simplifying assumptions: intra-sector labour mobility, international labour and capital immobility. The Core model assumes furthermore that the income gain is totally consumed and not invested. The release of those assumptions tend to mitigate or exacerbate the two effects but in general one gets that the initial shock leads to a subsequent real appreciation that negatively affects the activity of sector 
L.

In the case of the Canadian economy, on top of those effects, there might also be a direct effect linking the evolution of the nominal exchange rate and the price of commodities and oil. While the spending and the resource reallocation effects involve macroeconomic mechanisms, this last effect might be driven by speculation behaviours in the foreign exchange market. As explained by Corden (1984), the income and resource reallocation effects might be anticipated by agents. One way this anticipation is reflected in the real exchange rate is through speculation by traders on the value of the Canadian dollar. The growing importance of the commodity and energy goods sector in Canada might lead to a situation in which the Canadian dollar is considered as a commodity and oil currency.

To sum up, the theory yields two testable conditions under which one can conclude in favour of a Dutch disease phenomenon. First, there should be a relationship between the exogenous shock and the value of the currency. In our case, this means that there should be a relationship between the commodity and energy prices on the one hand and the value of the CAD on the other hand. Second, one should observe a decrease in the size of the trade exposed manufacturing sector, this decrease being partly driven by the rise in the value of the currency.

\subsection{Stylised facts: the Canadian case}

The case of Dutch disease in Canada has recently been revisited due to the concurrent evolution of a set of macroeconomic and financial variables. Figures 1 to 3 depict the evolution of the key variables involved in the debate. Figure 1 displays the evolution over the last 35 years of the bilateral CAD/USD exchange rates, both in real (plain line) and nominal (dotted line) terms. The figure plots the number of Canadian dollars per U.S. dollar. The dramatic appreciation of the CAD against the USD is easily identified for the last part of the period. Between the beginning of 2002 until the end of 2007, the CAD appreciated by about 48 per cent against the USD. ${ }^{7}$ A second interesting observation is that the real appreciation of the CAD against the USD comes almost exclusively from the nominal appreciation of the exchange rate. Indeed, the evolution of relative prices between Canada and the United States explains virtually nothing in the real evolution of the CAD/USD exchange rate. For the analysis of the Dutch disease, this implies that it is immaterial whether we work with the real or the nominal exchange rate.

Figure 2 plots, in real terms, the evolution of energy prices and prices of the other commodities. Both indices are deflated using the U.S. price index. The dramatic rise of oil and commodity prices beginning in 2002 is also highly visible from the plots. For the oil price, the level in real terms reaches an all-time high, even when compared with the level in the aftermath of the second oil shock. For the commodity prices, the recent rise appears to be more part of a catching-up process in historical terms.

Figure 3 reports the evolution over time of employment in the Canadian manufac-

\footnotetext{
${ }^{7}$ Actually, using daily data and taking the minimum value of the rate in 2002 and the maximum one in 2007, the maximal nominal appreciation amounts to 56 per cent.
} 


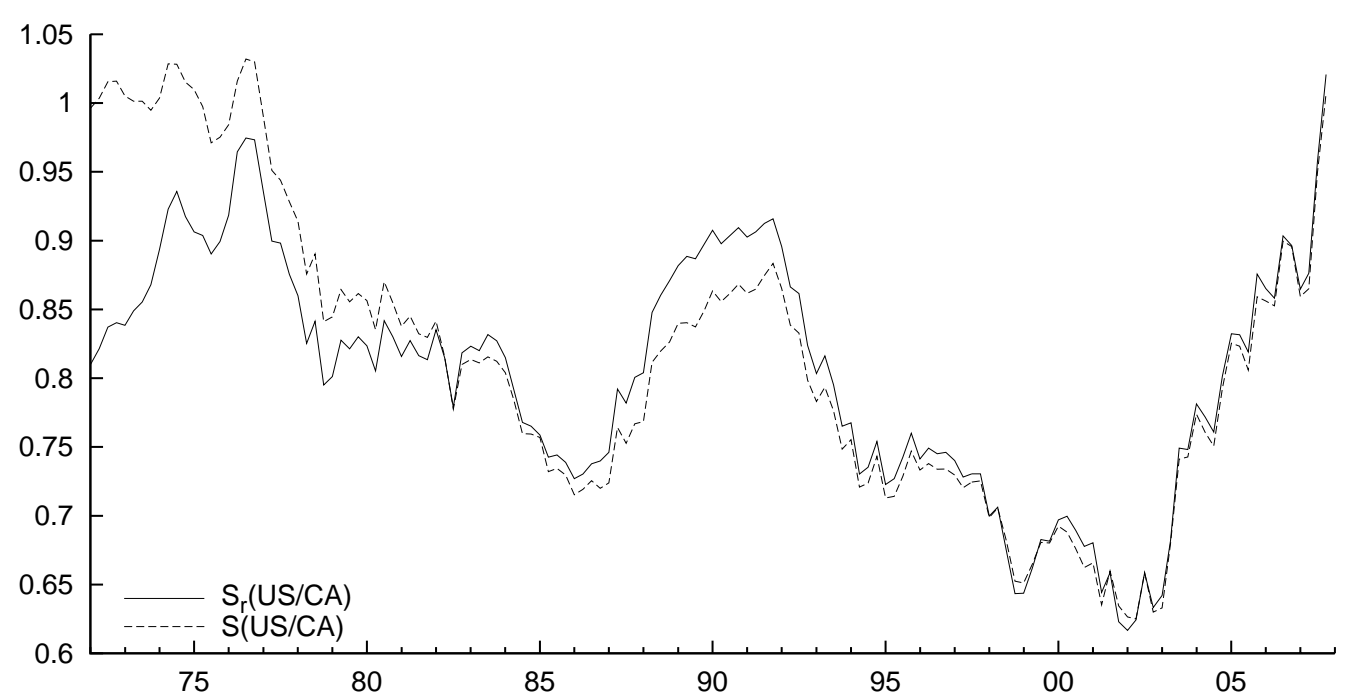

Figure 1: Nominal and real CAD/USD exchange rate

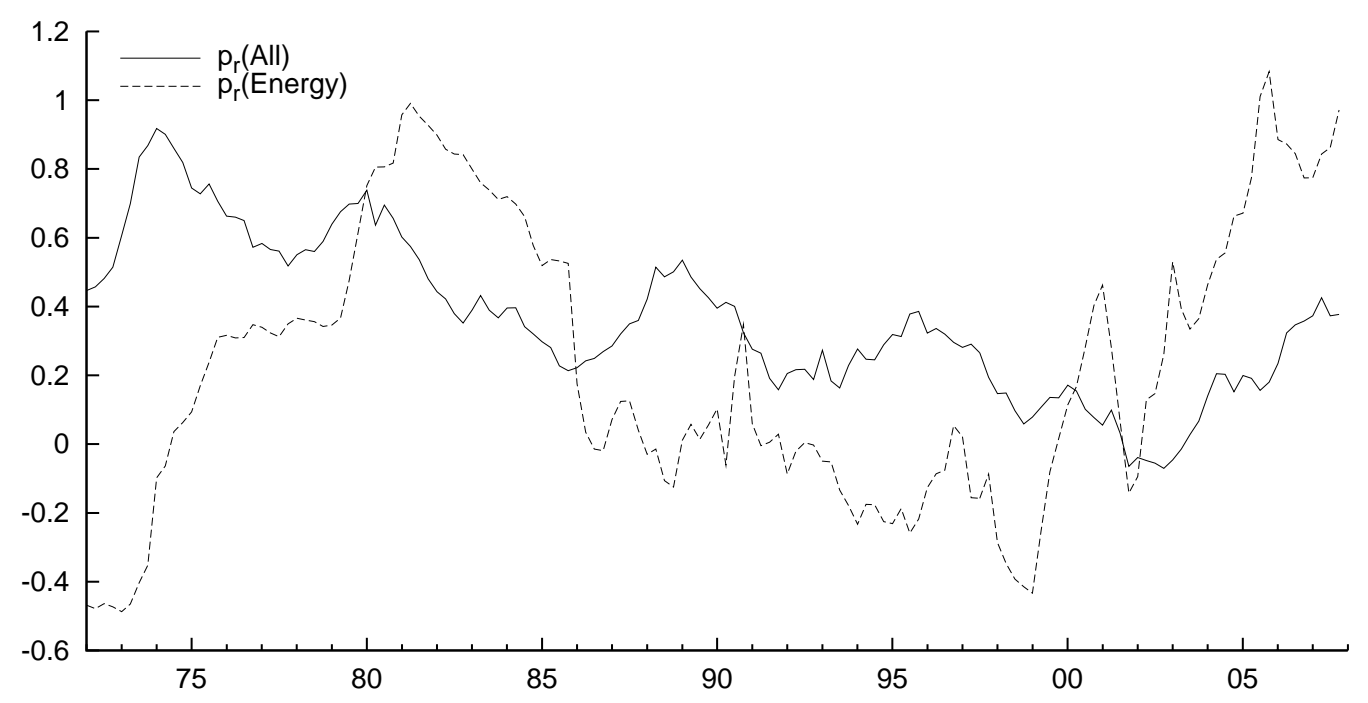

Figure 2: Evolution of real log-commodity prices: All commodities and energy 
turing sector as a share of total employment. The figure makes clear that the recent decrease in the relative part of the manufacturing sector is not an exceptional event. As in other industrialized countries, the share of Canadian manufacturing output tends to decrease in the long run due to the development of services. Nevertheless, what is striking is the relative speed with which this share decreased after 2001. The three concurrent evolutions after 2001-the appreciation of the CAD and USD, the strong increase in commodity and energy prices, and the rapid decrease in the size of the manufacturing sector-show that there is a potential case for Dutch disease in Canada. This has led many policy-makers to express grave concerns about the seriousness of such a phenomenon in Canada.

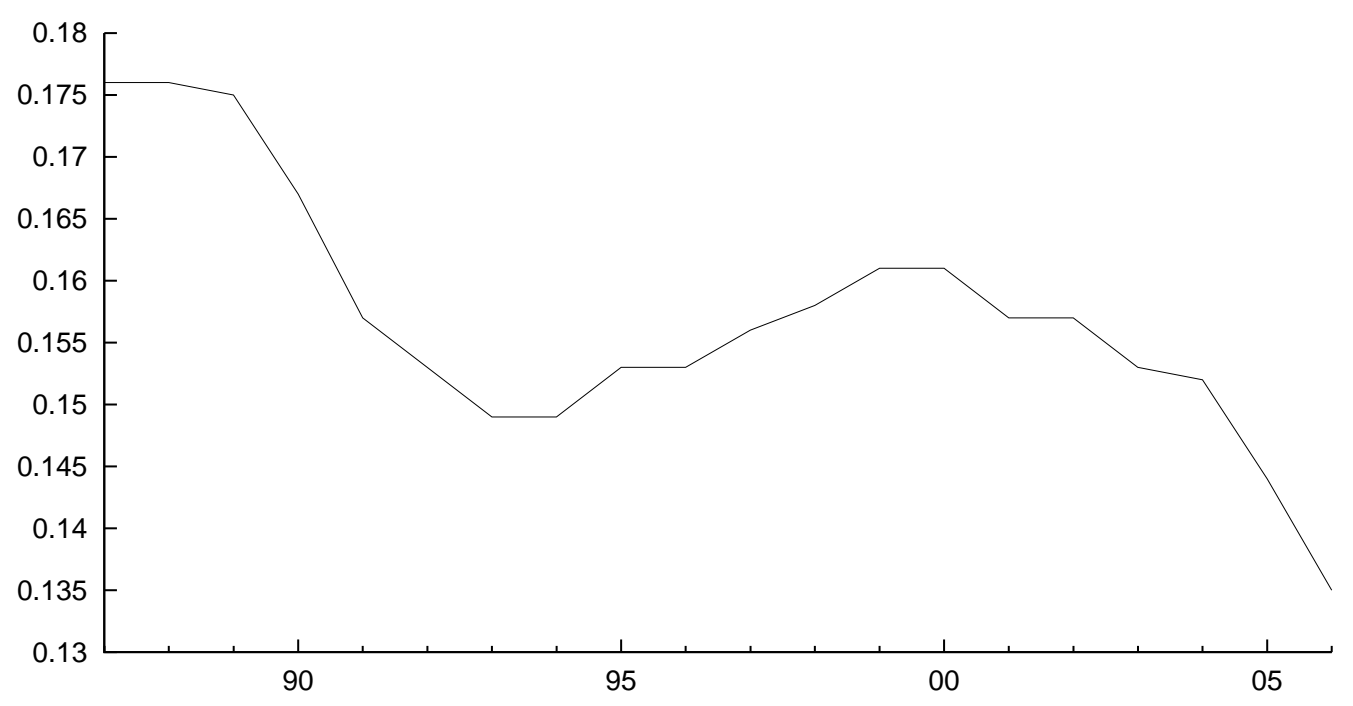

Figure 3: Canadian manufacturing employment as share of total employment

To what extent can we ascribe the decrease in manufacturing employment to the rise in oil prices? A first and important step is to test whether the evolution of the Canadian currency has been driven by the rise in commodity and oil prices. As mentioned above, most of the analyses have relied on the bilateral CAD/USD exchange rate, either in nominal or real terms. Such an approach exhibits one important weakness. The evolution of the CAD and USD is driven not only by the evolution of the Canadian currency but also by the evolution of the U.S. dollar that is unlikely to be driven by economic conditions in Canada. Had the USD been quite constant over the period under investigation, such an analysis could do the job. However, this is far from being true, especially over the sub-period of interest. Figure 4 shows the evolution of the nominal effective exchange rate of the USD over the 1973-2008 period. ${ }^{8}$ It is obvious that the U.S. dollar has depreciated significantly over this period against most of the currencies of the

\footnotetext{
${ }^{8}$ The data comes from Board of Governors of the Federal Reserve System. The series is a trade weighted exchange index of the USD involving the 7 major currencies (Series ID : TWEXM). An increase of the index corresponds to a global depreciation with respect to the other currencies.
} 
United States' trading partners, including of course the CAD. The weakness of the U.S. currency was widespread over this period and it needs to be analyzed separately from the evolution of the Canadian currency.

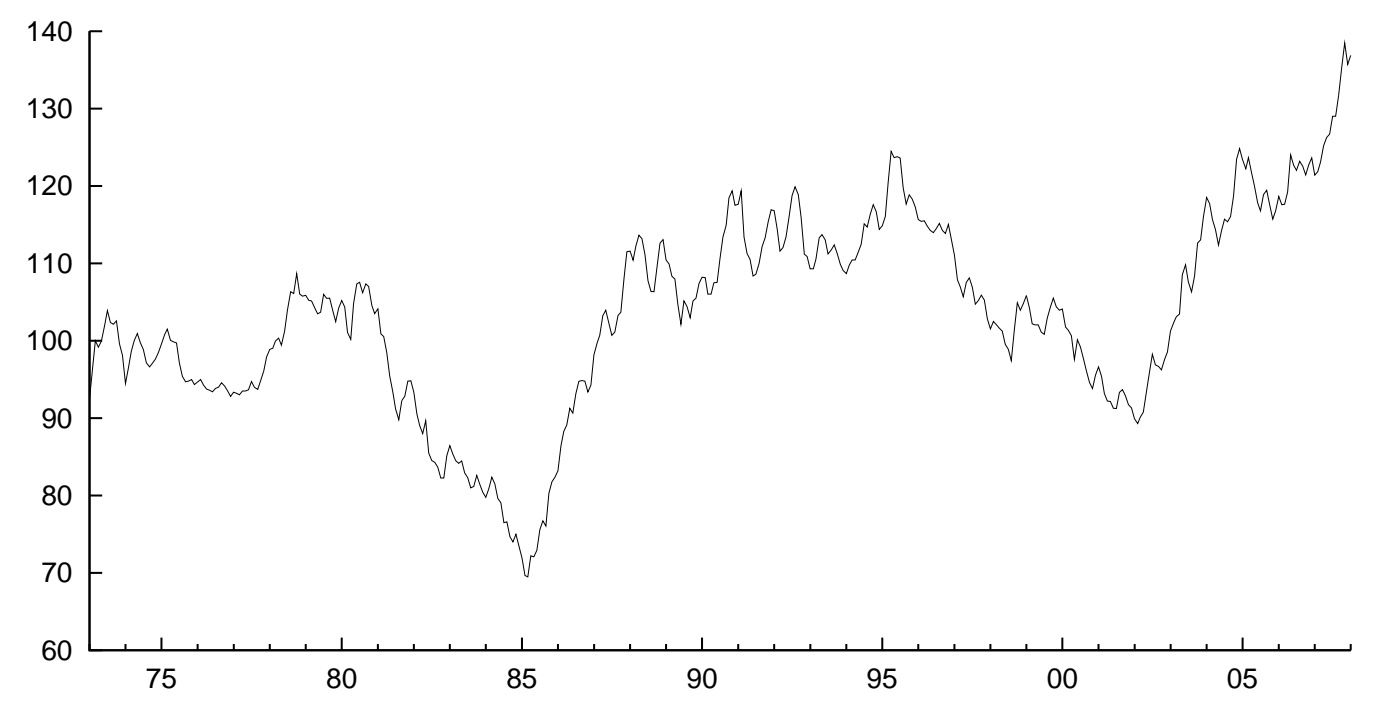

Figure 4: U.S. nominal effective exchange rate, 1973-2007

Will a separate analysis of the Canadian and the U.S. effective exchange rates solve this problem? Unfortunately not, because, the effective rate for Canada will be quite close to the bilateral CAD/USD exchange rate, given that a very high proportion of the Canadian trade is with the United States. After 1996, the weight of the USD used in computing the Canadian-dollar Effective Exchange Rate Index (CERI) amounts to about 76 per cent. This weight would be even more important if we were using the real proportion of the Canada's trade with the United States. This share has indeed increased over the last 30 years due to the implementation of the Canadian-U.S. Free Trade Agreement (see Beine and Coulombe, 2007). This is especially true after 1995 when the major part of the integration process had been completed. Figure 5 confirms that using the Canadian effective rate is useless. Over the last 15 years, one cannot see any significant difference among the nominal bilateral USD/CAD exchange rate (USD/CAD - continuous line), the nominal effective rate (Nom Eff CAD - dashed line) and the real effective exchange rate (Real Eff CAD - dotted line). As expected, the correlation among the three rates has increased over time, reflecting the high degree of integration of the Canadian and the U.S. economies.

Using the traditional measures of exchange rates, the issue seems to lead to a nonsolution conundrum. Indeed, what we need is an index of the Canadian currency that is fully independent of the U.S. currency. This paper offers a solution by relying on a new approach to measuring currency evolution. This approach was developed initially by Bos and Shephard (2006) and has been applied successfully in a number of exchange rate problems, such as the one concerning the impact of foreign exchange central bank inter- 


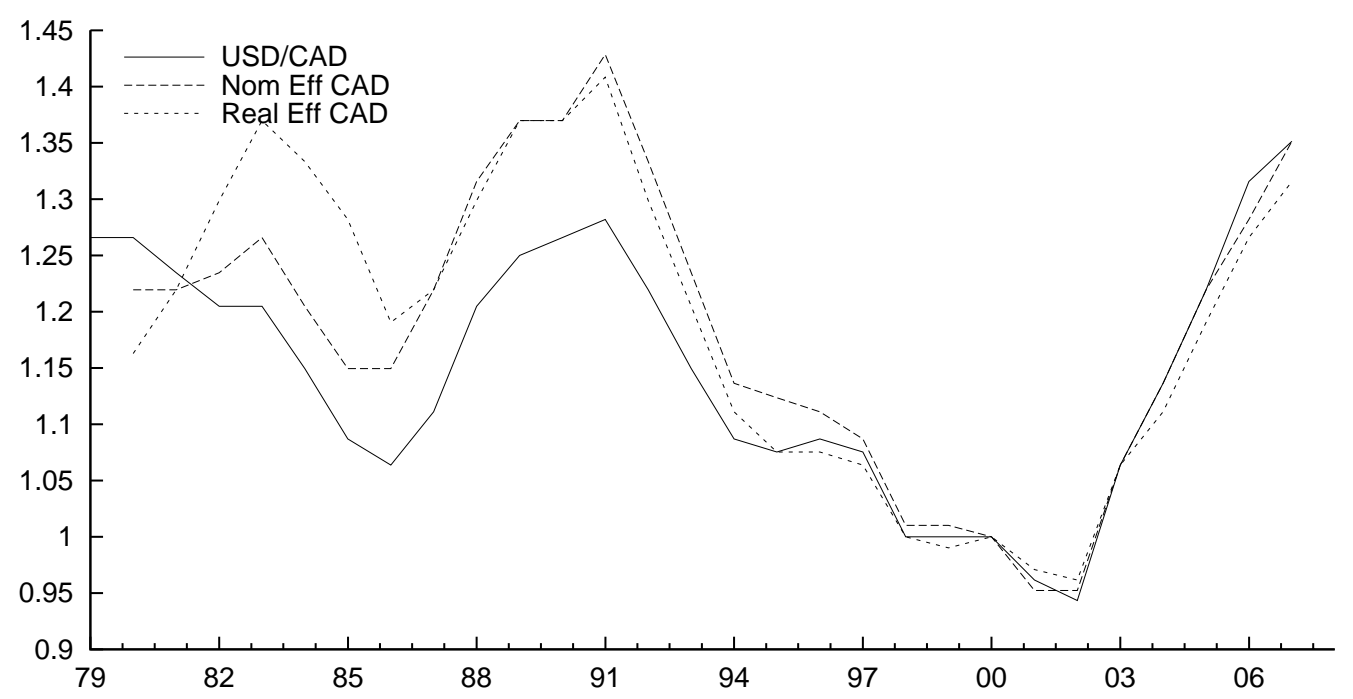

Figure 5: Evolution of Canadian-dollar exchange rates: Nominal USD/CAD, nominal effective $\mathrm{CAD}$, and real effective exchange rate

ventions (Beine et al. (2007)). For our purpose, the major advantage of this approach is that it allows the extraction of a currency index (called hereafter currency components) that is independent of any weighting scheme such as the trade weights used in the effective exchange rates. This approach and the resulting output are presented in the next section.

\section{Extracting currency components}

\subsection{Modelling the level and the volatility of currency components}

Following Bos and Shephard (2006), who build on work by Mahieu and Schotman (1994), we extract the movement in currency levels by describing the logarithm of the exchange rates as the difference between currency factors. For a system of $k$ exchange rates against a common denominating currency, there would be $k+1$ of such currency factors.

Though it is not possible to extract precisely the level of the $k+1$ factors out of $k$ observations of exchange rates, the movement of the exchange rates is informative about the relative movement of the underlying factors. Take, for instance, a situation in which the U.S. dollar is, on a specific day, weakening 5 per cent against both the British pound and the Japanese yen. This seems to imply that the U.S. currency factor dropped 5 per cent, with the pound and yen remaining stable. If the dollar dropped relative only to the pound but not to the yen, then the movement is more likely to have resulted from a (relative) strengthening of the pound.

To be able to quantify such movements, a formal model is described in Appendix A. In brief, the model assumes a random-walk-type behavior for the currency components. 
For simplicity, the currency components are assumed independent of the other currencies here.

The dissection into currency components automatically implies a correlated system of random walks for the log-exchange rates, as is often found in practice. As the currency markets display times of tranquility and others of hectic behavior, the variances of the random-walk increments are allowed to vary over time. The underlying system for the volatilities is the stochastic volatility model, with one volatility for each of the currencies separately. Although such a model is not "perfect" (for example, it does not explicitly model the jumps in the exchange rate when the Australian dollar is devalued in the earlier years of the sample), it gives a sufficiently rich description of the exchange rate movements for the present purpose.

Estimation is performed using a Bayesian Markov chain Monte Carlo (MCMC) method, to obtain estimates of the parameters and of the posterior mean of the currency level and volatility factors. The frequency of the daily level factors is lowered to the quarterly frequency, after which the resulting series are used in the analysis of the Dutch disease in Canada in Section 4.

For further details on the precise specification, and the estimation procedure, see Appendix A.

\subsection{Resulting currency factors, 1972-2007}

In the subsequent analysis, we use daily exchange rates of the U.S., Australian and Canadian dollars, the Japanese yen, and the British pound over the period of 3 January 1972 to 31 December 2007, for a total of 9391 days. Strictly speaking, we need only two exchange rates $(k=2)$ against the USD to extract the two currency components of interest, i.e., the CAD component and the USD component. Nevertheless, the use of the major currencies yields several advantages. First, the variation of the currency component might be interpreted as appreciations or depreciations against all the major currencies used in the international monetary system. This in turn provides a better way of capturing the variation in price competitiveness of the Canadian economy with respect to all the other trade competitors. Second, the use of a collection of 5 currencies allows a more precise estimation of the factor levels and their volatility. ${ }^{9}$

Figure 6 displays the factors for the United States and Canada over the full period (1972-2007). Similar factors are extracted for the other currencies but are displayed only in the appendix. The top panel displays the currency-level factor (continuous line, left-hand axis) together with the volatility factor (dashed line, right-hand axis) for the United States. Initially, little movement in both factors is seen, with few variations until 1980. The level of the U.S. component reflects the steady appreciation of the USD between 1980 and 1985, leading to the Plaza and the Louvre agreements and the subsequent depreciation of the U.S. currency until 1991. The moments of the sharp depreciations correspond to the sudden spikes in the extracted volatility. The period

\footnotetext{
${ }^{9}$ The German DMark and/or Euro is not included in the system, as these are not available over the full sample period.
} 
of 1994-1998 was exceptionally quiet for the U.S. dollar, with virtually no movement; this is also reflected in the low volatility over these years. This appears to have been a period when the other currencies seem to have evolved rather independently vis-à-vis the dollar; there were few occasions, for example, when all other currencies lost ground, implying a global appreciation of the U.S. currency. After 1998, the dollar increased in strength until 2002 when there was a steep decline in the value of the dollar against most other currencies. This decline continues over the last two years (2006 and 2007), although at a lower volatility than in the period of 2004-2006.
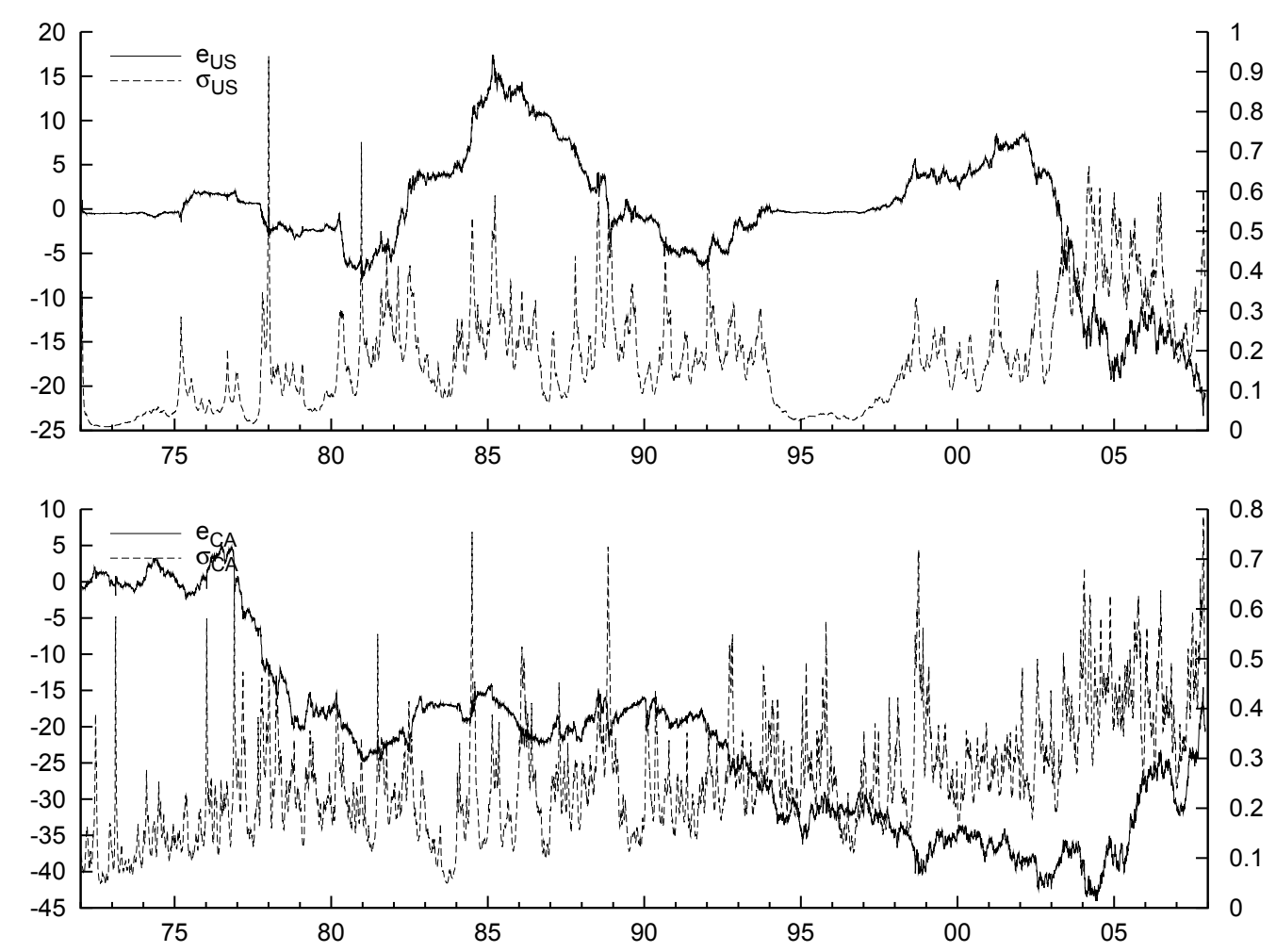

Figure 6: Evolution of currency levels (left-hand axis) and volatility (right-hand axis) for the U.S. dollar (upper panel) and the Canadian dollar (lower panel)

For Canada, there are fewer outstanding features. Uncertainty in the earliest periods was relatively low. A strong depreciation occurred throughout 1977-1979, with stability following throughout the 1980s. Uncertainty for the Canadian currency over 1994-1998 was considerably higher than for the U.S. currency; this may be partly because the CAD is not such an important international currency. From roughly 1990 onwards, a very slow but steady decline of the value of the currency is visible. Around 2003, however, the CAD started its rise against other currencies, with the rise broken only by intermittent spells of uncertainty and temporary depreciation.

The top panel of Figure 7 displays the log-price (times 100) of commodities, which, 
adapted for the U.S. currency factor $e_{\mathrm{US}}$ from Figure 6, delivers the commodity price factor $f_{\text {Commodity }}=p_{\text {textUS } / \text { Commodity }}-e_{\mathrm{US}}$. It is seen in Figure 7 how commodity prices rose over the years; however, in the latter years, an important part of the price hike was caused by the U.S. dollar's weakening in value. The final value of the commodity factor is, for instance, only marginally higher than its value in 1994 .
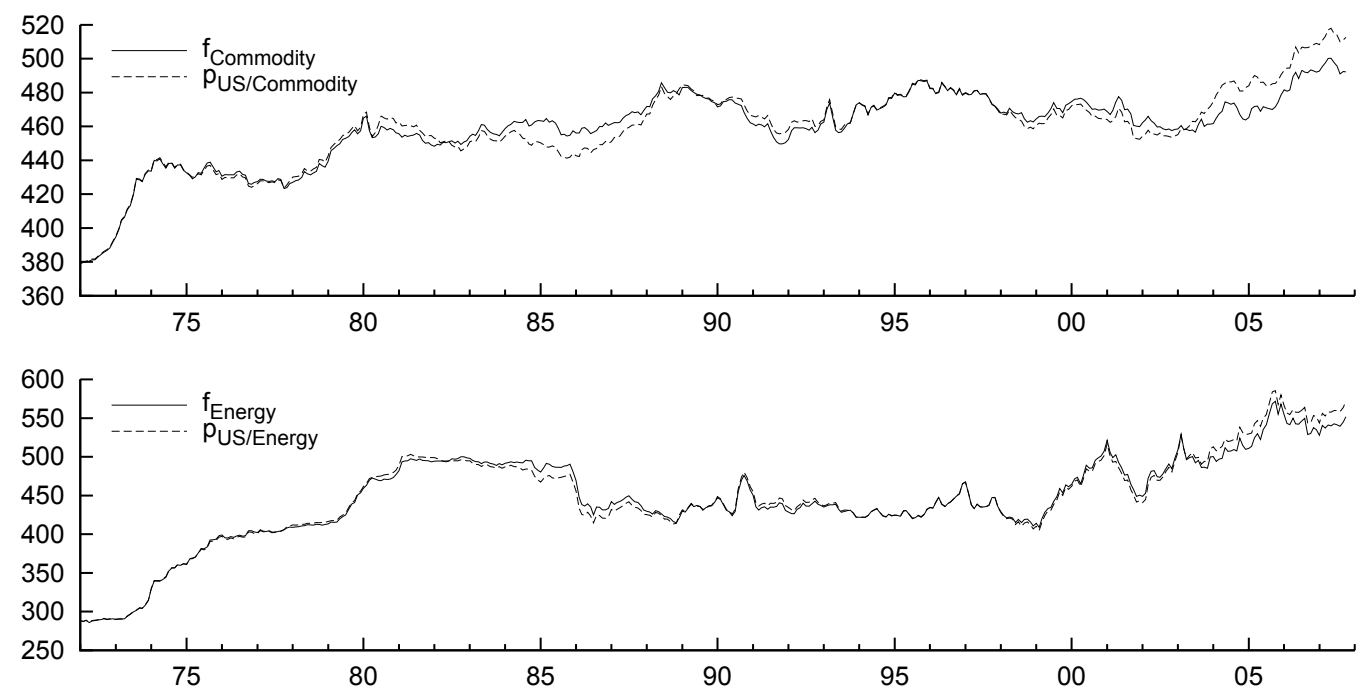

Figure 7: Evolution of the commodity (top) and energy (bottom) price factors $f$ (continuous line), together with corresponding log-prices $p$ (dashed line)

The price hike of energy, however, was far larger. Even after accounting for the currency effect, the resulting increase is still around 120 points over the last 13 years of the sample. As the prices are expressed on a logarithmic scale (multiplied by 100), this increase in the energy price since 1984 corresponds to a rise of roughly 120 per cent over the period.

Figure 8 plots the evolution of the extracted USD and CAD currency components jointly over the full period 1972-2007. Two comments are in order. First, our estimated components fully confirm that the sharp appreciation of the CAD/USD exchange rate is the result of two concomitant evolutions. The strong appreciation over the 2002-2007 period is the outcome of a severe weakening of the USD combined with a considerable strengthening of the Canadian currency with respect to other major currencies of the world. Second, our estimations allow us to extract the contribution of the two components to the appreciation of the CAD/USD over this period. Actually, 42 per cent (58 per cent) of the 48 per cent appreciation of the bilateral exchange rate is due to the strengthening (weakening) of the CAD (USD) component. Previous approaches based on the bilateral rate would end up ascribing the variations in commodity and energy prices to the total appreciation of the CAD/USD. We challenge this view and argue that it needs to be tested. While the evolution of Canada as a net exporter of primary products raises a case for the CAD to be a commodity currency over the last 25 years, 
there is little economic rationale to believe that the USD has been driven down by those prices. Alternative explanations, recently proposed, for instance by Obstfeld and Rogoff (2007) and emphasizing the role of the U.S. external imbalances, can be considered.

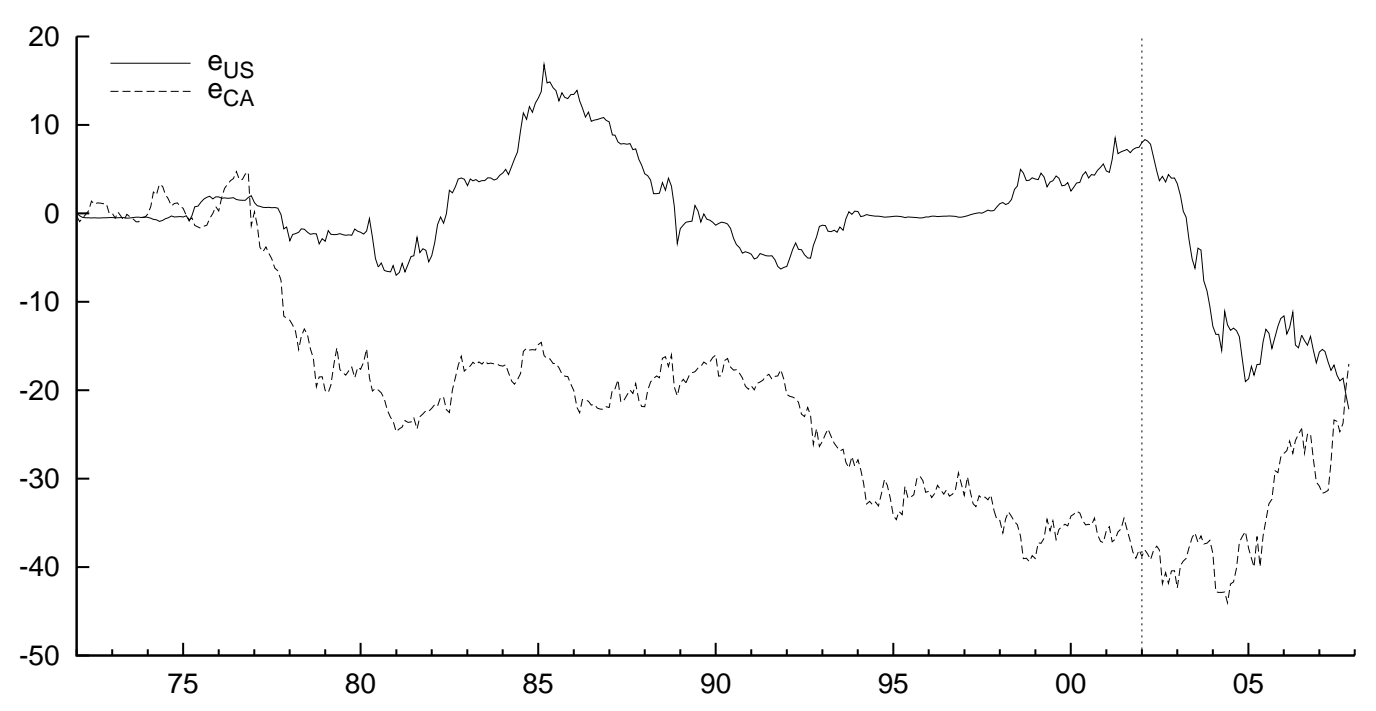

Figure 8: Evolution of the USD and CAD currency components

Another interesting insight provided by the extraction of the currency components is that the appreciation of the CAD/USD between 2002 and 2007 might be decomposed into two separate phases. During the first phase, ranging between 2002Q1 and 2004Q4, the CAD appreciated against the USD by 21 per cent; only 1.7 per cent (98.3 per cent) of this variation can be ascribed to the appreciation (depreciation) of the CAD component (of the USD component). In contrast, after 2004 and until the end of 2007, almost three quarters of the subsequent appreciation of the bilateral CAD/USD (this amounted to about 27 per cent) is due to the appreciation of the CAD component.

\section{Has the Canadian dollar become a commodity currency? Revisiting the Amano-van Norden equation}

Most of the empirical approaches testing the determinants of the CAD/USD exchange rate rely more or less on the early contribution of Amano and van Norden (1995). Basically, Amano and van Norden (1995) use an error correction model of the CAD/USD real exchange rate (over the 1973 M1-1992 M2 period) in which the long-run evolution depends on the prices of the exported energy and non-energy commodities. Furthermore, the short-run dynamics depends on the differential Canada-U.S. interest rate, which is found to be stationary $(\mathrm{I}(0)) \cdot{ }^{10}$ The main findings are the following. First, there is a

\footnotetext{
${ }^{10}$ More precisely, the interest rate variable involves the differential between the short-run - long-run differential between Canada and the United States.
} 
long-run relationship between the real exchange rate on the one hand and the energy and non-energy prices on the other hand. The speed of adjustment to the long-run equilibrium is such that the equilibrium is restored after about two years. Furthermore, endogeneity tests rule out any long-run reverse causality from prices to exchange rates. The second finding is a puzzle. While an increase in non-energy prices tend to appreciate the CAD, a rise in energy prices is found to depreciate the CAD in the long run. Finally, in line with intuition, an increase in the interest rate differential tends to appreciate the CAD.

Basically, the subsequent empirical analyses of the CAD/USD exchange rate update the estimations of Amano and van Norden (1995) and revisit the equation in different directions. Amano and van Norden's findings suggest that the long-run relationship between energy prices and the exchange rate is subject to structural breaks. Issa et al. (2006) find that the Amano-van Norden equation does not provide any explanatory power for the 1973-2005 period. Helliwell et al. (2004) do not find any robust relationship between commodity prices and the CAD. From preliminary data inspection, they do not consider a role for energy prices. Maier and DePratto (2008) find some evidence of a structural break in the relationship around 2002. They document that after 2002, the relationship between energy prices and the exchange rate might have changed, from a negative to a positive impact. The related question, which is not addressed by the authors, is why 2002 would be associated with a structural break. Bayoumi and Mühleisen (2006) provide an answer by introducing the Canadian net export position of energy goods. These net export positions are found to influence the long-run dynamics of the exchange rate and influence the way energy prices impact the rate in the short run. They suggest that the magnitude of the production and exports of the energy goods might condition the relationship between the commodity prices and the CAD/USD.

The extraction of each currency component allows us now to revisit the influence of the commodity and energy prices on the value of the CAD. To that end, we follow the Amano-van Norden approach and assess its relevance on each of the currency components, that is, the CAD component (denoted by eca $_{\text {) }}$ and the USD component (denoted by eus $_{t}$ ). For the sake of comparison, we also provide the same analysis on the bilateral CAD/USD real exchange rate, denoted by $r_{t}$. We consider three different periods: (i) the full period ranging from 1972Q2 (the starting period of the Amano-van Norden analysis) to 2007Q4; (ii) the 1972Q2-1993Q4 period, the period of the Amano-van Norden investigation; (iii) the 1983Q1-2007Q4 period during which Canada has become a net exporter of energy goods (see Bayoumi and Mühleisen, 2006). The results reported below are obtained with quarterly data. Nevertheless, it should be emphasized that we obtain strikingly similar results using monthly data. ${ }^{11}$

The starting underlying ECM equation of our analysis is written as

$$
\Delta x_{t}=\gamma_{1}-\gamma_{e} \Delta p_{e t}-\gamma_{n e} \Delta p_{n e t}-\gamma_{i d} i_{\text {diff } t-1}-\alpha x_{t-1}-\beta_{e} p_{e t-1}-\beta_{n e} p_{n e t-1}+\epsilon_{t}
$$

\footnotetext{
${ }^{11}$ The results are not reported here to save space but can be provided upon request. The similar results are not surprising given the fact that with long-run analyses involving $I(1)$ variables, the time span matters more than the frequency of the data. See Otero and Smith (2000) on this.
} 
where $x_{t}$ stands either for $r_{t}$, ecat, or eust. $p_{e t}$ and $p_{n e t}$ are the real energy and nonenergy prices, and $i_{\text {diff } t}$ is the differential between three-month nominal interest rates in Canada and the United States. ${ }^{12}$ The construction of the variables and the data sources are detailed in Appendix B. For the sake of interpretation, we define each dependent variable such that an increase of its value corresponds to a depreciation. An increase in $r_{t}, e c a_{t}$, and eus $_{t}$ therefore corresponds respectively to a real depreciation of the CAD against the USD, a depreciation of the CAD, and a depreciation of the USD. This means that, if energy prices and non-energy prices should go hand in hand with the CAD in the long run, we should have positive values for $\beta_{e}$ and $\beta_{n e}$. Equivalently, if increases in energy prices, in non-energy prices, and in the interest rate differential tend to appreciate the CAD in the short run, we should have positive values for $\gamma_{e}$ and $\gamma_{n e}, \gamma_{i d}$.

Tables 1, 2, and 3 present the estimation for $r_{t}$, eca , and eust. Basically, Table 1 reproduces (with the closest possible definition of the data) the approach of Amano and Van Norden and updates the estimations. The estimations over the 1972-1993 period are fully in line with the Amano-van Norden results. They suggest a good fit to the exchange rate data and leave open the puzzle of the non-intuitive sign for $\beta_{e}$. The results for the other sub-periods turn out to be much less promising. The hypothesis of a long-run equilibrium relationship between the real exchange rate and the commodity prices is rejected, either over the full period or over the last period. The estimations suggest that the Amano-van Norden equation involving the bilateral CAD/USD exchange rate is quite unstable. Even over the 1983-2007 period during which Canada became a net exporter of energy products, the speed of adjustment remains insignificant. From the subsequent analysis, we argue that such a failure to find some long-run relationship is due to fact that the bilateral rate is driven partly by the USD whose evolution is independent of the dynamics of the energy and commodity prices.

Table 2 provides the same results as in Table 1, but for the USD component. For all periods, the estimations strongly reject any long-run relationship between the commodity prices and the USD component. The Amano-van Norden equation explains virtually nothing of the U.S. component, as reflected by the very low $R^{2}$. The speed of adjustment to the long-run equilibrium is not significant over those periods. For the specific 1972-1993 period, we find evidence of a long-run correlation between the USD and the energy prices. Interestingly, a rise in real energy prices is found to appreciate the USD component. This result concurs with Amano and van Norden (1998) who show a positive long-run impact of oil prices on the U.S. real exchange rate over the same period. This might explain why, when the Amano-van Norden equation is applied to the bilat-

\footnotetext{
${ }^{12}$ Actually, for the regression involving $e c a_{t}$ (the Canadian component), one could have considered the energy and commodity price factors (plotted in Figure 7) that are not expressed in USD. We prefer to report results based on the use of energy and commodity prices in USD for two main reasons. First, this ensures that our results are fully comparable to those of Amano and van Norden (1995) who use prices expressed in USD. In turn, this allows to isolate the changes in the results due to the break down of the CAD/USD into the two currency components. Second, the use of the price factors raises the additional issue of generated regressors since those are estimated. Nevertheless, importantly, equation (1) for $x_{t}=e c a_{t}$ was reestimated using the price factors and the results as well as the conclusions of the analysis remain qualitatively identical.
} 
Table 1: Short and long-run determinants of the CAD/USD real exchange rate

\begin{tabular}{llllllll} 
& & $1972 \mathrm{Q} 2-2007 \mathrm{Q} 4$ & $1972 \mathrm{Q} 2-1993 \mathrm{Q} 4$ & \multicolumn{2}{c}{ 1983Q1-2007Q4 } \\
\hline$\gamma_{1}$ & Constant & 0.834 & $(1.53)$ & $7.094^{* * *}(1.59)$ & 2.195 & $(1.98)$ \\
$\gamma_{e}$ & Energy SR & $0.079^{* * *}(0.02)$ & 0.007 & $(0.02)$ & $0.085^{* * *}(0.02)$ \\
$\gamma_{n e}$ & Non-energy SR & $0.140^{* * *}(0.04)$ & 0.049 & $(0.04)$ & $0.143^{* *}$ & $(0.06)$ \\
$\gamma_{i d}$ & Int diff SR & 0.163 & $(0.15)$ & $0.687^{* * *}(0.15)$ & 0.245 & $(0.16)$ \\
$\alpha$ & Speed of adj & 0.021 & $(0.04)$ & $0.176^{* * *}(0.04)$ & 0.046 & $(0.05)$ \\
$\beta_{e}$ & Energy LR & $0.009^{*}$ & $(0.01)$ & $-0.019^{* * *}(0.01)$ & $0.020^{* *}$ & $(0.01)$ \\
$\beta_{n e}$ & Non-energy LR & 0.002 & $(0.02)$ & $0.067^{* * *}(0.02)$ & 0.024 & $(0.03)$ \\
\hline$R^{2}$ & 0.171 & & 0.366 & & 0.230 & \\
DW & 1.322 & & 1.166 & & 1.412 & \\
n obs & 143 & & 87 & & 100 & \\
\hline
\end{tabular}

Notes: Newey-West standard errors between parentheses; ${ }^{* * *}$, and ${ }^{* * *}$ denote significance at the 10,5 , and 1 per cent level.

eral rate, one finds evidence that a rise in the energy prices tended to depreciate rather than appreciate the CAD against the USD. Said differently, the non-intuitive sign of the impact of the energy prices in the original Amano-van Norden equation might be due to some correlation between the USD and the oil price.

Nevertheless, the relationship between the USD and energy prices seems specific to the Amano-van Norden period. For the full period and the recent one, to the extent that the USD component might be explained, the investigation should look at alternative determinants to those involving the commodity prices. One alternative explanation suggested by the work of Obstfeld and Rogoff (2007) is the evolution of the U.S. current account deficit. To test for such a relationship-given the failure of commodity prices to explain the evolution of the USD component (at least in the long run)-we consider the inclusion of the U.S. current account suplus as a share of GDP. Preliminary tests confirm that this variable is stationary over the present period; given its nature, this makes sense. Therefore, we consider the following alternative specification for the USD:

$$
\Delta e u s_{t}=\gamma_{1}-\gamma_{e} \Delta p_{e t}-\gamma_{n e} \Delta p_{n e t}-\gamma_{i d} i_{\text {diff } t-1}-\gamma_{u s c a} u s c a_{t-1}+\epsilon_{t}
$$

where $u s c a_{t}$ is the U.S. current account surplus as a share of GDP at time $t$. Columns (6) and (7) in Table 2 report the estimates over the 1983-2007 period. In column (6), OLS estimates are reported while in column (7), we use instrumental variable estimation using $u_{s c a_{t-2}}$ to prevent any endogeneity issue of the current account variable with respect to the U.S. currency. The estimations support the idea that the evolution of the USD is driven more by U.S. domestic variables such as the U.S. interest rate and the U.S. current account. The current account is significant at the 5 per cent level. The inclusion of the current account in the specification significantly improves its goodness of fit. Its sign is consistent with the idea that the adjustment of external imbalances might be carried out by a change in the U.S. currency. Since the current account collects imbalances with all U.S. partners, one should expect our currency component to capture the necessary 
Table 2: Short and long-run determinants of the USD component

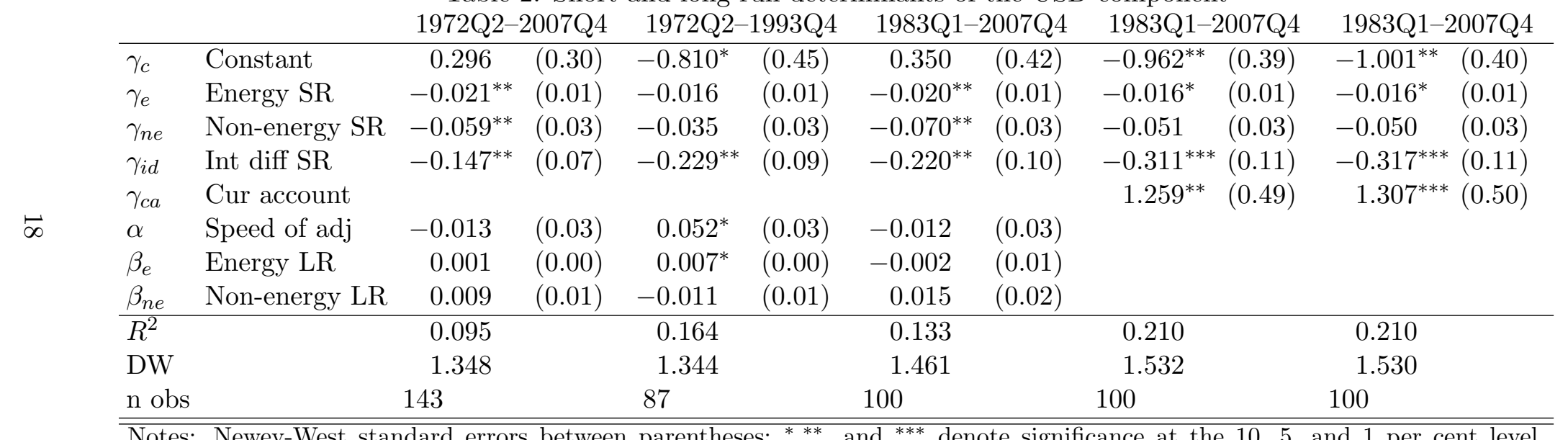

Columns (3-6): OLS estimations; Column (7): IV estimation; $u_{s c a_{t-1}}$ instrumented by $u_{s c a_{t-2}}$ 
adjustment better than the CAD/USD exchange rate. Given the size of the Canadian economy, the evolution of the U.S. current account is exogenous for Canada. Therefore, one can claim that part of the depreciation of the CAD/USD is due to factors on which the Canadian economic policy has virtually no impact. ${ }^{13}$

Let us turn now to the evolution of the CAD component. Table 3 provides the results of the Amano-van Norden framework for the CAD component. The results contrast with those applied to the bilateral rate and the USD component in many ways. First, over the 1972-1993 period, there is no long-run relationship between the Canadian currency and commodity prices. The $\alpha$ parameter is not significant at usual levels. This contrasts with the findings of the bilateral rate and the USD component. Our findings can explain the so-called Amano-van Norden puzzle, i.e., the seemingly non-intuitive sign for the long-run effect of energy prices on the CAD/USD. This non-intuitive sign is related to a positive correlation between the U.S. dollar and energy prices and has nothing to do with the evolution of the Canadian dollar over this period. Economically, this makes sense since Canada was not an important net exporter of oil and gas over this particular period (1972-1993). This contrasts with the most recent period, i.e., after 1983 (column (5)). The estimations reported in the last column show that over the 1983-2007 period, the Amano-van Norden equation explains strikingly well the evolution of the CAD component along with the energy and non-energy commodity prices. An increase in those commodity prices is found to lead to a long-run appreciation of the CAD currency and to some appreciation in the short run.

Table 3: Short and long-run determinants of the CAD component

\begin{tabular}{llcccccc} 
& & $1972 \mathrm{Q} 2-2007 \mathrm{Q} 4$ & $1972 \mathrm{Q} 2-1993 \mathrm{Q} 4$ & $1983 \mathrm{Q} 1-2007 \mathrm{Q} 4$ \\
\hline$\gamma_{c}$ & Constant & 1.920 & $(1.22)$ & $2.657^{* *}$ & $(1.22)$ & $4.591^{* * *}(1.13)$ \\
$\gamma_{e}$ & Energy SR & 0.025 & $(0.02)$ & -0.013 & $(0.02)$ & 0.025 & $(0.02)$ \\
$\gamma_{n e}$ & Non-energy SR & 0.037 & $(0.04)$ & 0.017 & $(0.03)$ & 0.031 & $(0.05)$ \\
$\gamma_{i d}$ & Int diff SR & 0.062 & $(0.10)$ & 0.168 & $(0.13)$ & $0.184^{*}$ & $(0.11)$ \\
$\alpha$ & Speed of adj & 0.047 & $(0.03)$ & 0.061 & $(0.04)$ & $0.104^{* * *}(0.03)$ \\
$\beta_{e}$ & Energy LR & 0.007 & $(0.00)$ & -0.005 & $(0.01)$ & $0.015^{* * *}(0.01)$ \\
$\beta_{n e}$ & Non-energy LR & 0.014 & $(0.01)$ & $0.026^{*}$ & $(0.01)$ & $0.054^{* * *}(0.01)$ \\
\hline$R^{2}$ & 0.085 & & 0.058 & & 0.204 \\
DW & 1.306 & & 1.203 & & 1.580 & \\
$\mathrm{n}$ obs & 143 & & 87 & & 100 \\
\hline
\end{tabular}

Notes: Newey-West standard errors between parentheses; ${ }^{*},{ }^{* *}$, and ${ }^{* * *}$ denote significance respectively at the 10,5 and 1 per cent level.

Let us summarize the main findings and implications.

\footnotetext{
${ }^{13}$ Interestingly, as an alternative to the USD component, one can conduct the same analysis with the effective USD exchange rate (depicted in Figure 4). The results obtained with the effective USD exchange rate are strikingly in line with those reported above : positive correlation between the USD and the energy prices only over the AvN period; no relationship over the other periods of investigation and positive impact of the US current account. The results are not reported here but are available upon request.
} 
- First, we find that the non-intuitive sign for the long-run impact of energy prices on the real CAD/USD exchange rate in the original Amano-van Norden equation is due to the fact that over this specific period, there is a positive correlation with the USD currency while no correlation with the CAD currency.

- In contrast, over the last period (1983-2007), we have exactly the opposite situation: the commodity prices affect the strength of the CAD currency while they have no effect at all on the U.S. dollar. This is line with the fact that, in the meantime, Canada has become a net exporter of commodities.

- Using the CAD and the USD components, our findings support the first condition needed to conclude in favour of Dutch disease in Canada. Nevertheless, one should qualify this as only a partial phenomenon because only at most 42 per cent of the appreciation of the CAD/USD is driven by commodity and energy prices. One should emphasize that using the traditional exchange rate measures such as the bilateral CAD/USD exchange rate, as is done in most of the recent literature, one would reject the case of a positive correlation between the Canadian currency and the commodity and energy prices. This would lead to conclude spuriously against the case of Dutch disease in Canada.

\section{The evolution of the Canadian dollar and the Dutch dis- ease: Specification and estimation techniques}

There is an extensive empirical literature dealing with the impact of exchange rate changes on employment changes at the industry level (see among others Campa and Goldberg (2001)). The effects of exchange rates are best captured in dynamic models of labour demand as explained in Nickell (1986). In line with those approaches, the effects of currency components on the Canadian manufacturing sectors are estimated using an adaptation of the time-series and cross-section empirical Error Correction Model used in Acharya and Coulombe (2008).

We pool annual Canadian and U.S. data for 21 industries over the 1987-2006 period. The endogenous variable, $s c a_{i t}$, is the share of employment in Canadian manufacturing industry $i$ (share of total employment) at time $t$. The change in $s c a_{i t}$ is regressed on the lagged share of employment in U.S. manufacturing sus $s_{i t-1}$, the lagged Canadian and U.S. currency components, the first difference of the first three controls, on its lagged level, and on industry fixed effects. The coefficient on the first difference of the Canadian component was never significant and was dropped. The $\epsilon_{i t}$ is an idiosyncratic error term:

$$
\begin{aligned}
\Delta s c a_{i t}=\alpha s c a_{i t-1}+\beta_{1} s u s_{i t-1}+\beta_{i 2} e c a_{t-1} & +\beta_{i 3} e u s_{t-1} \\
& +\beta_{4} \Delta e u s_{t}+\beta_{5} \Delta s u s_{i t}+\gamma_{i}+\epsilon_{i t} .
\end{aligned}
$$

Variable sus $_{i t-1}$, which has both a time-series and a cross-section dimension, is designed to control for structural changes and long-run trends that are industry specific. This variable, which is always highly significant, captures the effect of many potential controls 
that are time specific and industry specific. Its inclusion in the adjustment model allows us to capture unobserved factors explaining the differential evolution between Canadian and U.S. manufacturing employment. ${ }^{14}$

The reason for entering the Canadian and the U.S. currency components separately in regression (3), instead of combining them in a bilateral exchange rate, is two-fold. First, it aims at testing whether the two components affect industrial employment differently. There are obvious theoretical reasons to think that the effects are not identical. A depreciation in the U.S. dollar is likely to affect in the same way all exporters in the U.S. market (including Canadian firms) but will alter their competitiveness with respect to US producers. In contrast, a change in the Canadian component is likely to change the relative competitiveness of Canadian exporters with respect to all foreign competitors. This in turn implies that the effect of the two components is likely to differ across industries depending of the structure of the international competition for this particular industry. Second, we have shown that the two components are also driven by separate factors (resources versus strictly U.S. factors). Therefore, estimating the respective impact of each currency component provides an idea of the intensity of the Dutch disease phenomenon in Canada, both for the whole economy and for each manufacturing industry.

In the homogenous specification (Table 4 ), the $\beta_{i 2}$ and $\beta_{i 3}$ are constrained to be the same $\left(\beta_{2}\right.$ and $\left.\beta_{3}\right)$ across the $i$ 's. In contrast, the effects of the currency components are allowed to vary across industries in the heterogeneous specification (Table 5). Results from the heterogeneous specifications clearly indicate that the effect of currency components varies across industries. However, in the heterogeneous specification, the effects of the currency components are not estimated very accurately, given the limited number of time-series observations at hand. In the homogenous specification, the mean effects of the currency components are estimated more accurately since the slope coefficients are estimated using both the time-series and the cross-section dimensions.

Cross-section fixed effects are included in all estimations to control for some of the unobserved industry heterogeneity. Note that time dummies cannot be included since the currency components have only a time-series dimension. Industry-specific time trends are captured by the sus $i t-1$ variable.

In the homogenous specification, results are presented for Pooled Least Squares (PLS) and for Iterated Feasible Generalized Least Squares (IFGLS) estimates. PLS results are presented with Panel Corrected Standard Errors that are robust to heteroscedasticity. This approach is recognized to provide standard errors that do not lead to overconfidence (see Beck and Katz (1995)). ${ }^{15}$ IFGLS estimations account for cross-sectional

\footnotetext{
${ }^{14}$ Acharya and Coulombe (2008) experiment with a number of alternative controls such as industry tariffs (to capture the Canada-U.S. FTA) and various indexes of China import penetration. Generally speaking, these variables are not significant when the U.S. employment share variable is included in the regression.

${ }^{15}$ The potential drawback of both PLS and IFGLS is that the point estimate of the lagged dependent variable in equation (3) can be biased (see Kiviet (1995)). Non-reported results using Kiviet-corrected estimations provide, however, very similar results. Refer to Acharya and Coulombe (2008) for Kivietcorrected estimations. GMM estimations are inefficient with such a small number of cross-sections (see
} 
Table 4: Effect of currency components on Canadian industry employment: homogeneous specification

\begin{tabular}{|c|c|c|c|c|c|c|c|}
\hline \multirow[b]{2}{*}{ Parameter } & \multirow[b]{2}{*}{ Variable } & \multicolumn{3}{|c|}{ PLS } & \multicolumn{3}{|c|}{ IFGLS } \\
\hline & & Est & St. dev & LR elast & Est & St. dev & LR elast \\
\hline$\alpha$ & Lagged empl share & $-0.1581^{* * *}$ & $(0.030)$ & & $-0.1355^{* * *}$ & $(0.029)$ & \\
\hline$\beta_{1}$ & Lagged U.S. empl share & $0.0856^{* * *}$ & $(0.028)$ & 0.54 & $0.0965^{* * *}$ & $(0.027)$ & 0.71 \\
\hline$\beta_{2}$ & CA currency comp LR & $-0.0016^{* * *}$ & $(0.001)$ & 1.34 & $-0.0018^{* * *}$ & $(0.000)$ & 1.77 \\
\hline$\beta_{3}$ & US currency comp LR & $0.0023^{* * *}$ & $(0.000)$ & 1.86 & $0.0020^{* * *}$ & $(0.000)$ & 1.89 \\
\hline$\beta_{4}$ & US currency comp SR & 0.0009 & $(0.001)$ & & 0.0003 & $(0.001)$ & \\
\hline$\beta_{5}$ & Diff. U.S. empl share & $0.6159^{* * *}$ & $(0.096)$ & & $0.6310^{* * *}$ & $(0.112)$ & \\
\hline$R^{2}$ & & 0.1949 & & & 0.1749 & & \\
\hline DW & & 2.1826 & & & 2.1848 & & \\
\hline n obs & & 399 & & & 399 & & \\
\hline
\end{tabular}

Notes: Sample, 1987-2006 with 21 industries. Panel corrected (cross-section weights) standard error for PLS estimations between parentheses; ${ }^{* *}$, and ${ }^{* *}$ denote significance respectively at the 10,5 and 1 per cent level. 
heteroscedasticity and provide a slightly different picture from a quantitative point of view on the long-run elasticities. We provide results for long-run elasticities computed from the point estimates of specification (3). For the homogenous specification, the long-run elasticity of the share of U.S. employment is simply $-\hat{\beta}_{1} / \hat{\alpha}$. For the Canadian currency components, the elasticity is $-\hat{\beta}_{2} /(\overline{s c a} . . \hat{\alpha})$ where $\overline{s c a . .}$ is the mean across both $t$ and $i$ of the manufacturing industry share of Canadian employment. The U.S. currency component elasticity is measured accordingly with $\hat{\beta}_{3}$ instead of $\hat{\beta}_{2}$. For the heterogeneous specification, the long-run elasticities of the Canadian currency components for industry $i$ are computed as $-\hat{\beta}_{i 2} /\left(\overline{s c a_{i}} \hat{\alpha}\right)$ where $\overline{s c a_{i}}$. stands for the mean share across time of industry $i$. The U.S. currency component elasticities are measured accordingly with $\hat{\beta}_{i 3}$ instead of $\hat{\beta}_{i 2}$. In Tables 4 and 5 , elasticities are reported in absolute values.

All point estimates from the homogeneous specifications reported in Table 4 display the intuitive signs and are highly significant. The long-run elasticity of the share of U.S. employment is well below 1 , ranging between 0.54 and 0.71 . These point estimates indicate that the industry shares of Canadian manufacturing do not move one-for-one with the U.S. shares.

Interestingly, an appreciation of the CAD component and a depreciation of the USD component translate into a decrease in Canadian manufacturing employment shares. The point estimate for the USD component is larger (in absolute value) than that for the CAD component but the difference between the two is not significant. The long-run elasticities of the two currency components estimated from PLS are 1.34 and 1.86 for the CAD and USD components respectively. These numbers are similar with IFGLS estimations (1.77 and 1.89 respectively).

To shed some light on the importance of exchange rate developments in explaining the variation in Canadian manufacturing employment, we computed from the estimates of Table 4 the part of the explained variability of the variations of the Canadian industry shares accounted for by the three major variables, i.e., the corresponding U.S. share, the USD component, and the CAD component. It turns out that the CAD and the USD components account for, respectively, 6 per cent and 18 per cent of the explained variation in $\Delta s c a_{i t}$ over the 2002-2007 period, with the remaining 76 per cent being ascribed to the U.S. employment share variable. ${ }^{16}$

An appealing feature of the estimations of model (3) is that it allows us to rationalize results of previous estimations on the one hand and to overcome difficulties faced by alternative approaches on the other. Let us first begin with the results obtained by Acharya and Coulombe (2008). In their specification, Acharya and Coulombe (2008) find some explanatory power in the employment shares of manufacturing sectors for both the real exchange rate of the CAD and the price of oil over the 1988-2006 period.

Judson and Owen, 1999).

${ }^{16}$ The part of the CAD component for explaining the variability in $\Delta s c a_{i t}$ is computed as

$$
\frac{\hat{\beta}_{2} \Delta e c a_{2007-2002}}{\sum_{i} \hat{\beta}_{1} \Delta s u s_{i 2007-2002}+\hat{\beta}_{2} \Delta e c a_{2007-2002}+\hat{\beta}_{3} \Delta e u s_{2007-2002}} \times 100 .
$$

Note that the implied figures are very similar across the two estimation methods. 
These puzzling results might be rationalized using our findings since the price of oil is highly correlated with the Canadian dollar, and the USD real exchange rate captures, like our currency factor of the USD, the strength of the U.S. currency. Our results in Section 4 allow us to show that, by introducing the oil price, Acharya and Coulombe (2008) add a strong correlate of the Canadian dollar over this period.

Second, one might claim that introducing currency factors into model (3) is not necessary and that the impact of both currencies could instead be captured by introducing the effective exchange rates of the CAD and USD. This is definitely not correct. To illustrate this, we estimated alternative models with alternative variables capturing the strength of both currencies. ${ }^{17}$ We estimate three alternative specifications: (i) with both effective exchange rates; (ii) with the CAD effective exchange rate and the USD currency factor; and (iii) with the CAD currency factor and the USD effective exchange rate. In the first case, both exchange rates were not found to influence the industrial shares. In the second specification, only the CAD currency factor was found significant, while in the third specification, both variables were found to influence the employment shares. These results illustrate the effect of collinearity due to the high correlation between the traditional effective CAD exchange rate and the USD. In the first specification, the two effective exchange rates are highly correlated due to the trade weights of the U.S. economy for Canada. In the second specification, the same also occurs since the USD currency factor also captures the strength of the USD. In the third specification, one obtains similar results to those obtained with the currency components since the extraction of the CAD currency with the CAD factor breaks down the dependence of this indicator with respect to the USD. ${ }^{18}$

Point estimates of the currency components that vary across industries are displayed in Table 5, estimated using IFGLS. The speed of adjustment $\alpha$ is also reported and the point estimate (-0.377) is about twice as large as in the homogenous specification. This implies that the industries appear to adjust more rapidly when they are allowed to react differently to exchange rate changes.

Despite the lack of accuracy intrinsic to the estimation of the industry-specific slope coefficient with just 21 cross-sections at hand, 19 currency effects (out of 42) are significant at least at the 10 per cent level and only two have the counterintuitive sign.

From the point of view of the long-run elasticities, the three industries most affected by the Dutch disease are textile mills, machinery, and computer and electronics with elasticities ranging between 2.7 and 4.5. Plastics and rubber, and furniture are industries that are also more affected than the average by the Dutch disease with elasticities close to 2. The manufacturing industries-paper, printing, transportation equipment, and miscellaneous-are also affected negatively and significantly by the Dutch disease. All the affected industries, with the exception of printing, are highly exposed to international

\footnotetext{
${ }^{17}$ The results are not reported here to save space but can be obtained upon request.

${ }^{18}$ The results are not reported here to save space but are available upon request. Actually, the correlation between the USD effective exchange rate and the USD component amounts to 0.703 . In contrast with the effective CAD exchange rate, the USD effective exchange rate is not subject to issues of overweighed currency index since the US trade is much more diversified across destinations. The estimation results show that our original results are not driven by problems related to generated regressors.
} 
Table 5: Effect of currency components on Canadian industry employment: heterogeneous specification

\begin{tabular}{|c|c|c|c|c|}
\hline Industry & $\begin{array}{c}\text { CA currency } \\
\text { component }\end{array}$ & $\begin{array}{c}\text { LR } \\
\text { elasticity }\end{array}$ & $\begin{array}{l}\text { U.S. currency } \\
\text { component }\end{array}$ & $\begin{array}{c}\text { LR } \\
\text { elasticity }\end{array}$ \\
\hline Food Manufacturing & -0.0013 & & 0.0013 & \\
\hline Beverage and Tobacco & 0.0007 & & 0.0012 & \\
\hline Textile Mills & $-0.0025^{*}$ & 4.49 & -0.0004 & \\
\hline Textile Product & 0.0016 & & 0.0019 & \\
\hline Clothing Manuf. & -0.0021 & & $0.0040^{*}$ & 1.52 \\
\hline Leather \& Allied Prod. & -0.0003 & & 0.0004 & \\
\hline Wood Product & $-0.0047^{* * *}$ & 1.16 & 0.0030 & \\
\hline Paper & $0.0049^{* * *}$ & 1.41 & $0.0032^{* *}$ & 1.42 \\
\hline Printing & $-0.0039^{* *}$ & 1.47 & 0.0029 & \\
\hline Petroleum and Coal & 0.0009 & & 0.0003 & \\
\hline Chemical & $-0.0035^{* *}$ & 1.11 & 0.0023 & \\
\hline Plastics and Rubber & $-0.0062^{* * *}$ & 1.96 & 0.0016 & \\
\hline Non-Metallic Mineral & -0.0004 & & -0.0009 & \\
\hline Primary Metal & $0.0043^{* * *}$ & 1.33 & $0.0055^{* * *}$ & 2.40 \\
\hline Fabricated Metal & $-0.0053^{* * *}$ & 1.19 & -0.0002 & \\
\hline Machinery & $-0.0089^{* * *}$ & 2.96 & $0.0039^{*}$ & 0.77 \\
\hline Computer and Electro. & $-0.0083^{* * *}$ & 2.69 & -0.0017 & \\
\hline Electrical Equipment & -0.0011 & & 0.0023 & \\
\hline Transportation Equip. & $-0.0099^{* * *}$ & 1.27 & $0.0055^{* *}$ & 0.74 \\
\hline Furniture & $-0.0050^{* * *}$ & 1.88 & $0.0036^{* *}$ & 1.59 \\
\hline Miscellaneous & $-0.0038^{* * *}$ & 1.64 & 0.0000 & \\
\hline$\alpha$ speed of adj & \multicolumn{4}{|c|}{-0.3769} \\
\hline$R^{2}$ & \multicolumn{4}{|c|}{0.2738} \\
\hline DW & \multicolumn{4}{|c|}{2.1974} \\
\hline TSCS obs & \multicolumn{4}{|c|}{399} \\
\hline Cross-section obs & \multicolumn{4}{|c|}{21} \\
\hline
\end{tabular}

Notes: Sample 1987-2006 with 21 industries. The effect of other controls in specification (3) not displayed. White cross-section standard errors between parentheses; ${ }^{*},{ }^{* *}$, and ${ }^{* * *}$ denote significance respectively at the 10,5 , and 1 per cent level. The insignificant LR elasticties are not displayed. 
trade. ${ }^{19}$ There is no systematic pattern between the degree of technology intensity (following the OECD classification for low-, medium-, and high-tech industries) and the degree of exposure to the Dutch disease.

The elasticities for the long-run effect of the U.S. currency component for the six industries for which the effect is significant vary between 0.74 and 2.4. With the exception of primary metal, the other industries affected by the U.S. component are highly exposed to international trade. Again, no relationship is observed between the degree of technology intensity and the exposure to the U.S. component. The industries that are affected by the two currency components with the intuitive signs are machinery, transportation equipment, and furniture. The only industry that is affected only by the U.S. currency components is clothing manufacturing. The industries that are affected only by the Canadian currency components are textile mills, wood product, printing, chemical, plastics and rubber, fabricated metal, computer and electronics, and miscellaneous.

Industries that are not affected by either currency component are food manufacturing, beverage and tobacco, textile product, leather and allied product, petroleum and coal, non-metallic mineral, and electrical equipment.

Finally, the point estimates reported in Table 4, coupled with the respective appreciation of the CAD component and the depreciation of the USD component observed between 2002 and 2008, can be used to provide the comparative contribution of these two factors to the exchange rate effect on Canadian manufacturing employment over the recent period. What emerges from the exercise is that, depending on the estimation method, between 33 and 39 per cent of the decline in employment related to exchange rate developments comes from the appreciation of the CAD component; the remaining 61 to 66 per cent comes from the depreciation of the USD component. This result is driven by the fact that, over the period, the change in the CAD component was much larger than the change in the USD component. In this respect, we can argue that the Canadian economy has been subject to a partial Dutch disease phenomenon. It is partial in both ways: in its macroeconomic impact and partial in the sense it affected a subset of industries only.

\section{Conclusion}

In this paper, we have investigated the extent to which the Canadian economy has been subject to the Dutch disease phenomenon. We argue that the use of the bilateral CAD/USD exchange rate is likely to mislead the analysis of the Dutch disease in the case of the Canadian economy. The reason is that the evolution of the CAD/USD exchange rate might be driven by factors that affect only the USD. The use of the effective exchange rate of the CAD, which relies on a weighting scheme based on trade, is of little help to solve this issue since it is highly correlated with the bilateral CAD/USD exchange rate. In this paper, we propose a new solution that allows us to disentangle exchange rates into currency components that capture the strength of the respective

\footnotetext{
${ }^{19}$ We follow here and thereafter the taxonomy established by Dion (2000) to classify the industries according to their degree of trade exposure.
} 
currencies. Significantly, the decomposition is independent of the trade weights usually used to define effective exchange rates.

Our results challenge the conclusion of the Amano and van Norden (1995) exchange rate equation linking the evolution of the CAD/USD exchange rate to the price of oil and natural resources. Our results also provide new insights into the determinants of the CAD. First, we show that the counterintuitive sign of the oil price in the CAD/USD exchange rate of Amano and van Norden (1995) is due exclusively to a positive correlation of the USD with the oil price over this particular period (1972-1993). Second, we show that over the recent period during which Canada has been a net exporter of oil and primary products (1983 onwards), the Canadian currency has been driven up by the price of commodities. In contrast, the evolution of the USD seems disconnected from that of prices of oil and primary products but appears driven rather by U.S.-specific factors such as the evolution of the U.S. current account deficit. Significantly, using traditional exchange rate measures such as the bilateral CAD/USD exchange rate or the effective CAD exchange rate as done in the existing literature would lead to rejecting a long-run relationship between the energy and commodity prices and the Canadian currency. This in turn would lead to spurious conclusions regarding the case of Dutch disease in Canada.

Using our decomposition, we show that the appreciation of the CAD explains about $42 \%$ of the sharp appreciation of the CAD/USD exchange rate over the 2002-2008 period. The sharp depreciation of the USD over the same period explains the rest of the appreciation of the CAD/USD exchange rate. In turn, both evolutions are responsible for the losses in the Canadian manufacturing sector, with roughly similar quantitative effects but with some differences at the industry level. All in all, this allows us to assess the extent to which the Canadian economy has been subject to the Dutch disease in the recent period. It is also clearly shown that the depreciation of the U.S. dollar worsened the situation. Analyses failing to account for this last evolution are likely to yield a deformed picture of the situation and in turn to lead to inappropriate policies.

The substantial appreciation of the CAD/USD exchange rate between 2002 and mid2008 has been followed by a sharp depreciation of about 20 per cent in the last quarter of 2008. Over the same period, the price of oil and the other commodities returned to very low levels. ${ }^{20}$ The recent developments are a good illustration as to why the Dutch disease should be taken into account in understanding the evolution of the Canadian economic structure and its future well-being. As pointed out at the beginning of this paper, the Dutch phenomenon becomes a disease if the manufacturing sector does not rebound when the resource boom is over. Had Alberta's resource boom lasted for 100 years, the appreciation of the Canadian currency and the shrinking of its manufacturing sector might have been viewed as an optimal market adjustment with a limited role for government intervention. However, as the Alberta resource boom is already part of history, the Dutch phenomenon may have already become a disease that challenges economic policy. We believe our paper might be of some help in understanding the

\footnotetext{
${ }^{20}$ In January 2009, the price of a barrel of light sweet crude oil was under US $\$ 40$, having fallen from US $\$ 145$ in June 2008, and the CAD/USD exchange rate was just above 0.80 .
} 
recent evolution and the future challenges for the Canadian economy. 


\section{A Econometrics of component modelling}

The input for the analysis of components is a vector $s_{t}=\left(s_{1 t}, \ldots, s_{k t}\right)$ of $k$ log-exchange rates $s_{i 1}=100 \log S_{i t}$ against a common currency. The common currency will be indicated by index 0 . Each of the log-exchange rates is written as the difference between the currency factor of country $i, e_{i t}$, and the common currency factor, $e_{0 t}$, as in

$$
\mathbf{s}_{t}=\left(\begin{array}{c}
e_{1 t} \\
e_{2 t} \\
\vdots \\
e_{k t}
\end{array}\right)-e_{0 t}=\mathbf{e}_{1: k t}-e_{0 t} .
$$

Instead of modelling the log-exchange rates directly, an independent random-walk structure for the factors is proposed,

$$
\mathbf{e}_{t+1}=\mathbf{e}_{t}+\eta_{t} \quad \eta_{t} \sim \mathcal{N}\left(0, \Sigma_{e t}\right)
$$

with $\Sigma_{e t}$ a $k+1 \times k+1$ diagonal matrix with currency factor variances $\sigma_{i t}, i=0, \ldots, k$ on the diagonal. Finally, the disturbances $\eta_{t}$ are assumed to be independent over time.

As volatilities clearly move to different levels over a sample as long as the one used in the present application, a standard first order autoregressive specification for the log-variance is implemented. This stochastic volatility model is specified as

$$
\log \sigma_{i t+1}^{2}=\gamma_{i}+\phi_{i}\left(\log \sigma_{i t}^{2}-\gamma_{i}\right)+\xi_{t} \quad \xi_{i t} \sim \mathcal{N}\left(0, \sigma_{i \xi}^{2}\right) .
$$

Essentially, all log-variances can change over time independently of what happens in the rest of the model; the variances of the individual increments are $\sigma_{i \xi}^{2}$.

For identification, the common currency factor is initialized at $e_{0} 0=0$, leaving the other factors to start at the value of the log-exchange rate. The initial value of the variances $\sigma_{i t}^{2}$ is estimated along with the vector of parameters $\theta=\left(\phi^{\prime}, \gamma^{\prime}, \sigma_{\xi}^{\prime}\right)$. Estimation of the resulting non-linear state space model (Harvey, 1989) is performed using a Markov Chain Monte Carlo (MCMC) approach (see also Jacquier et al., 1994). A straightforward MCMC algorithm with data augmentation delivers good convergence properties for the model at hand. Notice that, for estimation of the parameters $\theta$, alternative methods such as simulated maximum likelihood or GMM-based methods could be used. These alternative methods, however, are not as good as the Bayesian simulation approach for extracting the posterior mean of the currency and volatility factors.

The model was implemented in the Ox (Doornik, 2007) using routines from SsfPack (Koopman et al., 2008). The final results are collected by first sampling a burn-in sample of 10,000 iterations, followed by a posterior sample of 100,000 iterations. Such a sample was sufficiently large, as especially the currency factors were found to converge swiftly. Table 6 displays the moments of the Beta, normal and IG-1 prior densities for the parameters $\phi, \gamma$ and $\sigma_{\xi}$ respectively, together with the mode, mean, standard deviation, and 95 per cent highest posterior density regions of the posterior sample. Note that the prior densities were chosen based on previous experience, purposely taking priors with 
Table 6: Prior and posterior for model parameters

\begin{tabular}{lrr|rrrc} 
& \multicolumn{2}{c|}{ Prior } & \multicolumn{4}{|c}{ Posterior } \\
& Mean & St. dev & Mode & Mean & St. dev & $95 \%$ HPD \\
\hline$\phi(\mathrm{US})$ & 0.864 & $(0.10)$ & 0.992 & 0.991 & $(0.00)$ & {$[0.989,0.994]$} \\
$\phi(\mathrm{AU})$ & 0.864 & $(0.10)$ & 0.936 & 0.936 & $(0.01)$ & {$[0.923,0.948]$} \\
$\phi(\mathrm{CA})$ & 0.864 & $(0.10)$ & 0.967 & 0.965 & $(0.01)$ & {$[0.955,0.975]$} \\
$\phi(\mathrm{JA})$ & 0.864 & $(0.10)$ & 0.915 & 0.917 & $(0.01)$ & {$[0.900,0.932]$} \\
$\phi(\mathrm{UK})$ & 0.864 & $(0.10)$ & 0.948 & 0.946 & $(0.01)$ & {$[0.932,0.957]$} \\
$\gamma(\mathrm{US})$ & 0.000 & $(2.00)$ & -4.064 & -4.049 & $(0.31)$ & {$[-4.658,-3.439]$} \\
$\gamma(\mathrm{AU})$ & 0.000 & $(2.00)$ & -2.010 & -2.014 & $(0.09)$ & {$[-2.182,-1.847]$} \\
$\gamma(\mathrm{CA})$ & 0.000 & $(2.00)$ & -3.001 & -2.995 & $(0.09)$ & {$[-3.174,-2.816]$} \\
$\gamma(\mathrm{JA})$ & 0.000 & $(2.00)$ & -1.670 & -1.667 & $(0.06)$ & {$[-1.790,-1.542]$} \\
$\gamma(\mathrm{UK})$ & 0.000 & $(2.00)$ & -2.013 & -2.004 & $(0.08)$ & {$[-2.168,-1.838]$} \\
$\sigma_{H}(\mathrm{US})$ & 0.504 & $(0.20)$ & 1.872 & 1.908 & $(0.14)$ & {$[1.657,2.193]$} \\
$\sigma_{H}(\mathrm{AU})$ & 0.504 & $(0.20)$ & 1.441 & 1.444 & $(0.05)$ & {$[1.352,1.541]$} \\
$\sigma_{H}(\mathrm{CA})$ & 0.504 & $(0.20)$ & 1.092 & 1.101 & $(0.05)$ & {$[1.005,1.210]$} \\
$\sigma_{H}(\mathrm{JA})$ & 0.504 & $(0.20)$ & 1.188 & 1.194 & $(0.04)$ & {$[1.122,1.271]$} \\
$\sigma_{H}(\mathrm{UK})$ & 0.504 & $(0.20)$ & 1.305 & 1.304 & $(0.05)$ & {$[1.214,1.402]$} \\
\hline \hline
\end{tabular}

relatively large standard deviations, to allow the data to decide on the final location of the posterior density.

Back in Figure 6 the evolution of the level and the volatility of the Canadian and U.S. currency factors were displayed. Figure 9 reports the evolution of these components for the other currencies involved in the estimation, i.e., the Australian dollar, the Japanese yen, and the British pound over the 1972Q1-2007Q4 period.

\section{B Data sources and variable definitions}

- $S_{t}$ : vector of daily exchange rates against the USD (number of USD for one unit of domestic currency): Canadian dollar (CAD), British pound (UKP), Japanese yen (JPY), Australian dollar (AUS). Source: Datastream.

- $E_{t}$ : Canadian nominal effective exchange rate, trade-weighted (code: V37426). Source: Statistics Canada CANSIM II.

- $P_{t}$ : Bivariate vector of monthly commodity price indexes:

- Total commodity price index excluding energy in USD terms $(1980=100)$ (code V36383). Source: Statistics Canada CANSIM II.

- Energy price index in USD terms $(1980=100)$ (code V36383). Source: Statistics Canada CANSIM II. 

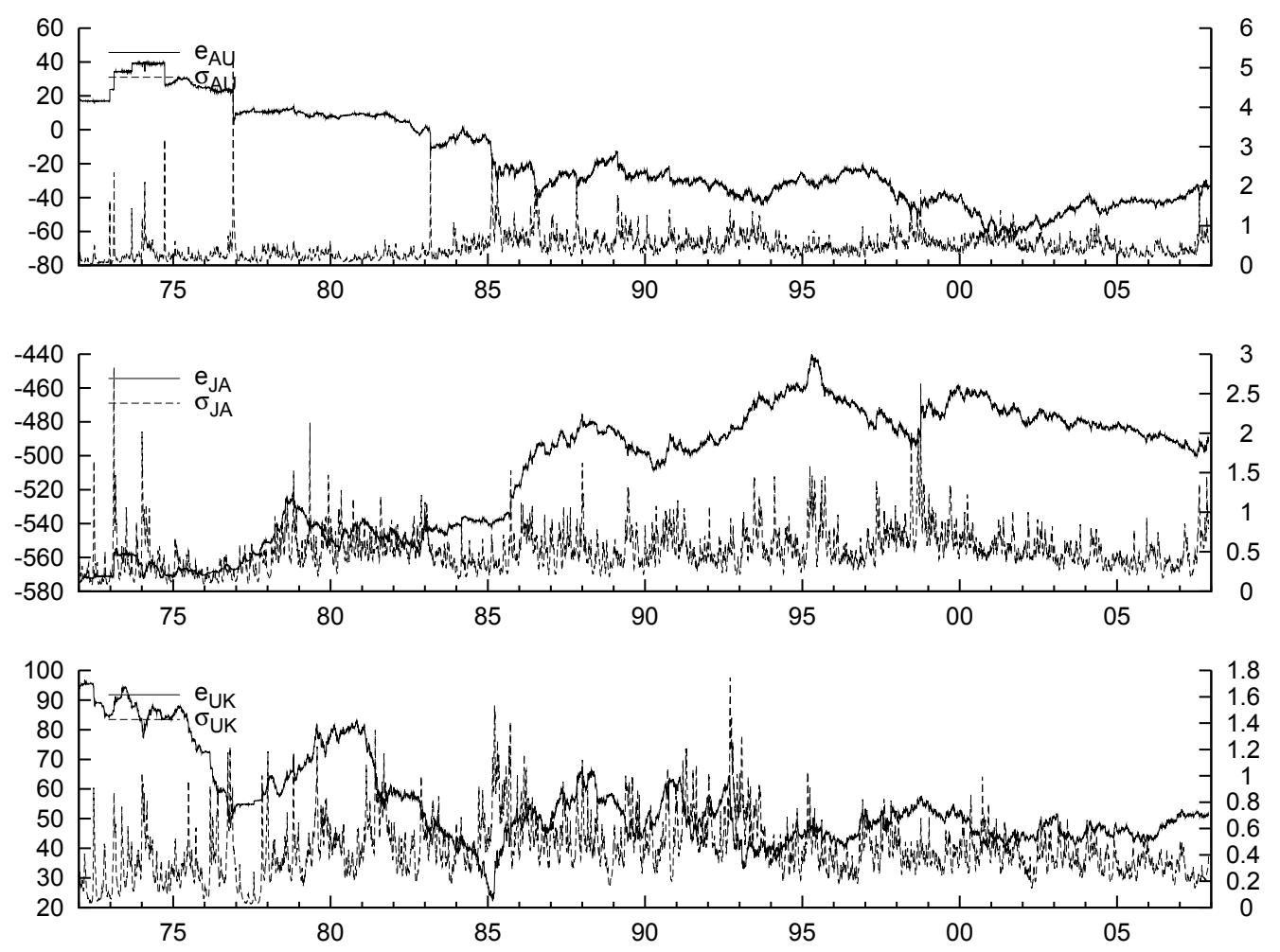

Figure 9: Currency components (levels and volatility) of the other currencies 
- $q_{\mathrm{US}, t}$ : Monthly U.S. GDP deflator $(2000=100)$, computed by the ratio of gross domestic product current dollars (code V121951) and gross domestic product chained 2000 dollars (code v21581591). Source: Statistics Canada CANSIM II.

- $q_{\mathrm{CA}, t}$ : Monthly Canadian GDP deflator $(2000=100)$, implicit price index $(2002=100)$ (code V1997756). Source: Statistics Canada CANSIM II.

- $r_{t}=\log \frac{1}{S_{t}} \frac{q_{\mathrm{US}, t}}{q_{\mathrm{CA}, t}}: \log$ of the real CAD/USD exchange rate

- $i_{\text {diff } t}: 3$-month interest rate differential between Canada and the United States, monthly frequency; computed as $i_{\mathrm{diff} t}=i_{\mathrm{CA} t}-i_{\mathrm{US} t}$ where $i_{\mathrm{CA} t}$ is the 3 -month prime corporate paper rate (code: V122491) and $i_{\mathrm{US} t}$ is the U.S. 3-month commercial paper rate adjusted (code V122141). Source: Statistics Canada CANSIM II.

- $s c a_{i t}$ : share of employment of industry $i$ in total manufacturing employment in Canada at time $t$ (annual frequency). Source: Labour Force Survey, Statistics Canada.

- sus $_{i t}$ : share of employment of industry $i$ in total manufacturing employment in the United States at time $t$ (annual frequency). Source : U.S. Labor Force survey, U.S. Bureau of Labor Statistics.

- Net interprovincial migration (footnote 2) (code v391142). Source: Statistics Canada CANSIM II.

\section{References}

Acharya, R. C. and S. Coulombe (2008). Exchange rate, energy prices, and employment restructuring in Canada. Unpublished manuscript.

Amano, R. A. and S. van Norden (1995). Terms of trade and real exchange rates: The Canadian evidence. Journal of International Money and Finance 14(1), 83-104.

Amano, R. A. and S. van Norden (1998). Oil prices and the rise and fall of the US real exchange rate. Journal of International Money and Finance 17(2), 299-316.

Bayoumi, T. and M. Mühleisen (2006). Energy, the exchange rate, and the economy: Macroeconomic benefits of Canada's oil sands production. Working paper WP/06/70, IMF. 
Beck, N. and J. N. Katz (1995). What to do (and not to do) with time series cross-section data. American Political Science Review 89(3), 634-647.

Beine, M., C. S. Bos, and S. Laurent (2007). The impact of central bank FX interventions on currency components. Journal of Financial Econometrics 5(1), 154-183.

Beine, M. and S. Coulombe (2007). Economic integration and the diversification of regional exports: Evidence from the Canadian-U.S. free trade agreement. Journal of Economic Geography 7(1), 93-111.

Bos, C. S. and N. Shephard (2006). Inference for adaptive time series models: Stochastic volatility and conditionally Gaussian state space form. Econometric Reviews 25(2-3), 219-244.

Campa, J. M. and L. S. Goldberg (2001). Employment versus wage adjustment and the U.S. dollar. Review of Economics and Statistics 83(3), 477-489.

Corden, W. M. (1984). Booming sector and dutch disease economics: Survey and consolidation. Oxford Economic Papers 36(3), 359-380.

Corden, W. M. and J. P. Neary (1982). Booming sector and de-industrialisation in a small open economy. Economic Journal 92(368), 825-848.

Coulombe, S., R. Lamy, and S. Rogers (2007). Adjustments in high trade exposed manufacturing employment in Canada. Unpublished manuscript.

Dion, R. (1999-2000). Trends in Canada's merchandise trade. Bank of Canada Review Winter, 29-41.

Doornik, J. A. (2007). Ox5: An Object-Oriented Matrix Programming Language. London: Timberlake Consultants Ltd.

Gylfason, T. (2001). Natural resources, education, and economic development. European Economic Review 45(4-6), 847-859.

Gylfason, T., T. T. Herbertsson, and G. Zoega (1999). A mixed blessing: Natural resources and economic growth. Macroeconomic Dynamics 3, 204-225.

Harvey, A. C. (1989). Forecasting, Structural Time Series Models and the Kalman Filter. Cambridge: Cambridge University Press.

Helliwell, J. F., R. Issa, R. Lafrance, and Q. Zhang (2004). NEMO: An equation for the Canadian dollar. Conference proceedings "canada in the global economy". http://www. bankof canada.ca/en/conference/2004/nemo.pdf.

Issa, R., R. Lafrance, and J. Murray (2006). The turning black tide: Energy prices and the Canadian dollar. Working paper 2006-29, Bank of Canada. 
Jacquier, E., N. G. Polson, and P. E. Rossi (1994). Bayesian analysis of stochastic volatility models (with discussion). Journal of Business and Economic Statistics 12(4), 371-417.

Judson, R. A. and A. L. Owen (1999). Estimating dynamic panel data models: A guide for macroeconomists. Economics Letters 65(1), 9-15.

Kiviet, J. F. (1995). On bias, inconsistency, and efficiency of various estimators in dynamic panel data models. Journal of Econometrics 68(1), 53-78.

Koopman, S. J., N. Shephard, and J. A. Doornik (2008). SsfPack 3.0: Statistical Algorithms for Models in State Space Models. London: Timberlake Consultants Ltd.

Krugman, P. (1987). The narrow moving band, the Dutch disease, and the competitive consequences of Mrs. Thatcher: Notes on trade in the presence of dynamic scale economies. Journal of Development Economics 27(1-2), 41-55.

Krugman, P. (1991). Increasing returns and economic geography. Journal of Political Economy 99(3), 483-499.

Mahieu, R. J. and P. C. Schotman (1994). Neglected common factors in exchange rate volatility. Journal of Empirical Finance 1(3-4), 279-311.

Maier, P. and B. DePratto (2008). The Canadian dollar and commodity prices: Has the relationship changed over time? Discussion Paper 2008-15, Bank of Canada.

Nickell, S. J. (1986). Dynamic models of labour demand. In O. Ashenfelter and R. Layard (Eds.), Handbook of Labor Economics, Vol. 1, pp. 473-522. Amsterdam: NorthHolland.

Obstfeld, M. and K. S. Rogoff (2007). The unsustainable US current account position revisited. Working paper 10869, NBER.

Otero, J. and J. Smith (2000). Testing for cointegration: Power versus frequency of observation - further Monte Carlo results. Economics Letters 67(1), 5-9.

Sachs, J. D. and A. M. Warner (1995). Natural resource abundance and economic growth. Working paper 5398, NBER.

Sachs, J. D. and A. M. Warner (1999). The big push, natural resource booms and growth. Journal of Development Economics 59(1), 43-76.

Stijns, J.-P. C. (2005). Natural resource abundance and economic growth revisited. Resources Policy 30(2), 107-130.

Venables, A. J. (1996). Equilibrium locations of vertically linked industries. International Economic Review 37(2), 341-359. 